\title{
The archaeal COG1901/DUF358 SPOUT-methyltransferase members, together with pseudouridine synthase Pus10, catalyze the formation of 1 -methylpseudouridine at position 54 of $t R N A$
}

\author{
KUNAL CHATTERJEE, ${ }^{1,5}$ IAN K. BLABY ${ }^{2,5,6}$ PATRICK C. THIAVILLE, ${ }^{2}$ MRINMOYEE MAJUMDER, ${ }^{1}$ \\ HENRI GROSJEAN, ${ }^{3}$ Y. ADAM YUAN, ${ }^{4}$ RAMESH GUPTA, $^{1,7}$ and VALÉRIE DE CRÉCY-LAGARD ${ }^{2,7}$ \\ ${ }^{1}$ Department of Biochemistry and Molecular Biology, Southern Illinois University, Carbondale, Illinois 62901-4413, USA \\ ${ }^{2}$ Department of Microbiology \& Cell Science, University of Florida, Gainesville, Florida 32611-0700, USA \\ ${ }^{3}$ Université Paris11, IGM, CNRS, UMR 8621, Orsay, F 91405, France \\ ${ }^{4}$ Department of Biological Sciences and Temasek Life Sciences Laboratory, National University of Singapore, Singapore, 117543
}

\begin{abstract}
The methylation of pseudouridine $(\Psi)$ at position 54 of tRNA, producing $m^{1} \Psi$, is a hallmark of many archaeal species, but the specific methylase involved in the formation of this modification had yet to be characterized. A comparative genomics analysis had previously identified COG1901 (DUF358), part of the SPOUT superfamily, as a candidate for this missing methylase family. To test this prediction, the COG1901 encoding gene, $\mathrm{HVO}_{-}$1989, was deleted from the Haloferax volcanii genome. Analyses of modified base contents indicated that while $m^{1} \Psi$ was present in tRNA extracted from the wild-type strain, it was absent from tRNA extracted from the mutant strain. Expression of the gene encoding COG1901 from Halobacterium sp. NRC-1, VNG1980C, complemented the $\mathrm{m}^{1} \Psi$ minus phenotype of the $\Delta H V O_{-} 1989$ strain. This in vivo validation was extended with in vitro tests. Using the COG1901 recombinant enzyme from Methanocaldococcus jannaschii (Mj1640), purified enzyme Pus10

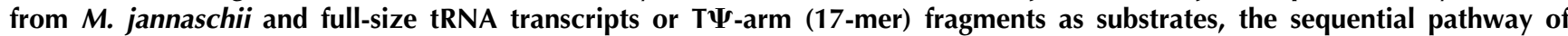
$\mathrm{m}^{1} \Psi 54$ formation in Archaea was reconstituted. The methylation reaction is AdoMet dependent. The efficiency of the methylase reaction depended on the identity of the residue at position 55 of the T $\Psi$-loop. The presence of $\Psi 55$ allowed the efficient conversion of $\Psi 54$ to $\mathrm{m}^{\mathbf{1}} \Psi 54$, whereas in the presence of $\mathrm{C55}$, the reaction was rather inefficient and no methylation reaction occurred if a purine was present at this position. These results led to renaming the Archaeal COG1901 members as TrmY proteins.
\end{abstract}

Keywords: tRNA modification; tRNA methylation; Haloferax volcanii; TrmY; Archaea

\section{INTRODUCTION}

Transfer RNAs in all three domains of life contain a large variety of characteristic post-transcriptionally modified nucleosides. Among them pseudouridine, an isomer of uridine (abbreviated $\Psi$ ) and base or ribose methylations $(\mathrm{mN}$, or $\mathrm{Nm}$ respectively; $\mathrm{N}$ being any of the four bases $\mathrm{A}, \mathrm{U}, \mathrm{C}$, or $\mathrm{G}$ ) are by far the most abundant (all listed in Czerwoniec

\footnotetext{
${ }^{5}$ These authors contributed equally to this work.

${ }^{6}$ Present address: Department of Chemistry and Biochemistry, University of California, Los Angeles, CA 90095-1569, USA.

${ }^{7}$ Corresponding authors.

E-mail rgupta@siumed.edu.

E-mail vcrecy@ufl.edu.

Article published online ahead of print. Article and publication date are at http://www.rnajournal.org/cgi/doi/10.1261/rna.030841.111.
}

et al. 2009; Cantara et al. 2011) (for review, see Grosjean 2009; Motorin and Helm 2011). Many of these noncanonical nucleotides are highly conserved at specific sites in functionally important parts of tRNA molecules. For example $\Psi, \mathrm{m}^{5} \mathrm{U}$ (riboT), or $\mathrm{m}^{1} \Psi$ are nearly always found at position 54 in the so-called $\mathrm{T} \Psi$-loop at the elbow of the L-shaped tRNA molecules, while $\Psi$ is found at the neighboring position 55. The conservation of these modifications at these two positions is certainly due to essential structural roles. Indeed, the presence of $\Psi 55$ reinforces tertiary basepairing with the conserved G18, favors intra-loop stacking with the conserved purine at position 57 and with the neighboring $\mathrm{m}^{5} \mathrm{U} 54 / \mathrm{m}^{1} \Psi 54$ engaged in a reverse-Hoogsteen pair with the conserved A58 (Romby et al. 1987). Together with the conserved tertiary pair C56-G19 between the T $\Psi$ loop and D-loop, this "ensemble" of conserved interacting 
nucleotides allows crucial interactions that form a stable "tertiary core" and, hence, the canonical tRNA L-shape architecture (Kotlova et al. 2007 and references therein). In agreement with this "locking" function of both $\Psi 55$ and $\mathrm{m}^{5} \mathrm{U} 54$ (probably also $\mathrm{m}^{1} \Psi 54$ in archaeal tRNAs, see below), these base modifications are among the earliest to appear during the complex tRNA maturation process (Nishikura and De Robertis 1981; Grosjean et al. 1996).

Even if the modifications at position 54 and 55 are conserved and have critical structural roles, strains lacking these modifications are viable. A mutant of Escherichia coli deleted in the $t r u B$ gene (encoding for the $\Psi 55$ producing enzyme) grew normally on all media tested (Gutgsell et al. 2000). It did exhibit a competitive disadvantage in extended co-culture with its wild-type progenitor and a defect in surviving rapid transfers from $37^{\circ} \mathrm{C}$ to $50^{\circ} \mathrm{C}$ (Gutgsell et al. 2000). Moreover, combining truB mutations with mutations affecting the catalytic activity of TrmA, the enzyme catalyz- ing the formation of the adjacent $\mathrm{m}^{5} \mathrm{U} 54$, further increased the temperature sensitivity phenotype (Kinghorn et al. 2002).

In the present work, we focus on the biosynthesis of 1-methylpseudouridine in tRNAs $\left(\mathrm{m}^{1} \Psi 54\right)$ (Fig. 1A). This $\Psi$ derivative was first characterized from the bulk tRNA of archaeon Halococcus morrhuae (Pang et al. 1982). It has now been found in tRNAs isolated from many Archaea, mainly Euryarchaeota (Table 1). Its location at position 54 of tRNA was inferred from sequence analysis of 41 tRNAs from $H$. volcanii (Gupta 1984, 1986). In contrast, tRNA sequences from Thermoplasma acidophilum (two sequences), Methanobacterium thermoautotrophicum (one sequence), and Sulfolobus acidocaldarius (one sequence) revealed the presence of a nonmethylated $\Psi$ or a ribose-methylated U (Um) in place of $\mathrm{m}^{1} \Psi 54$ (Cantara et al. 2011; http://www.unibayreuth.de/departments/biochemie/trna/). In tRNAs from Thermococcales (Pyrococcus furiosus and Pyrococcus abyssi), $\mathrm{m}^{5} \mathrm{U} 54$ or $\mathrm{s}^{2} \mathrm{~m}^{5} \mathrm{U} 54$ are found instead of $\mathrm{m}^{1} \Psi 54$ (Fig. 1A;

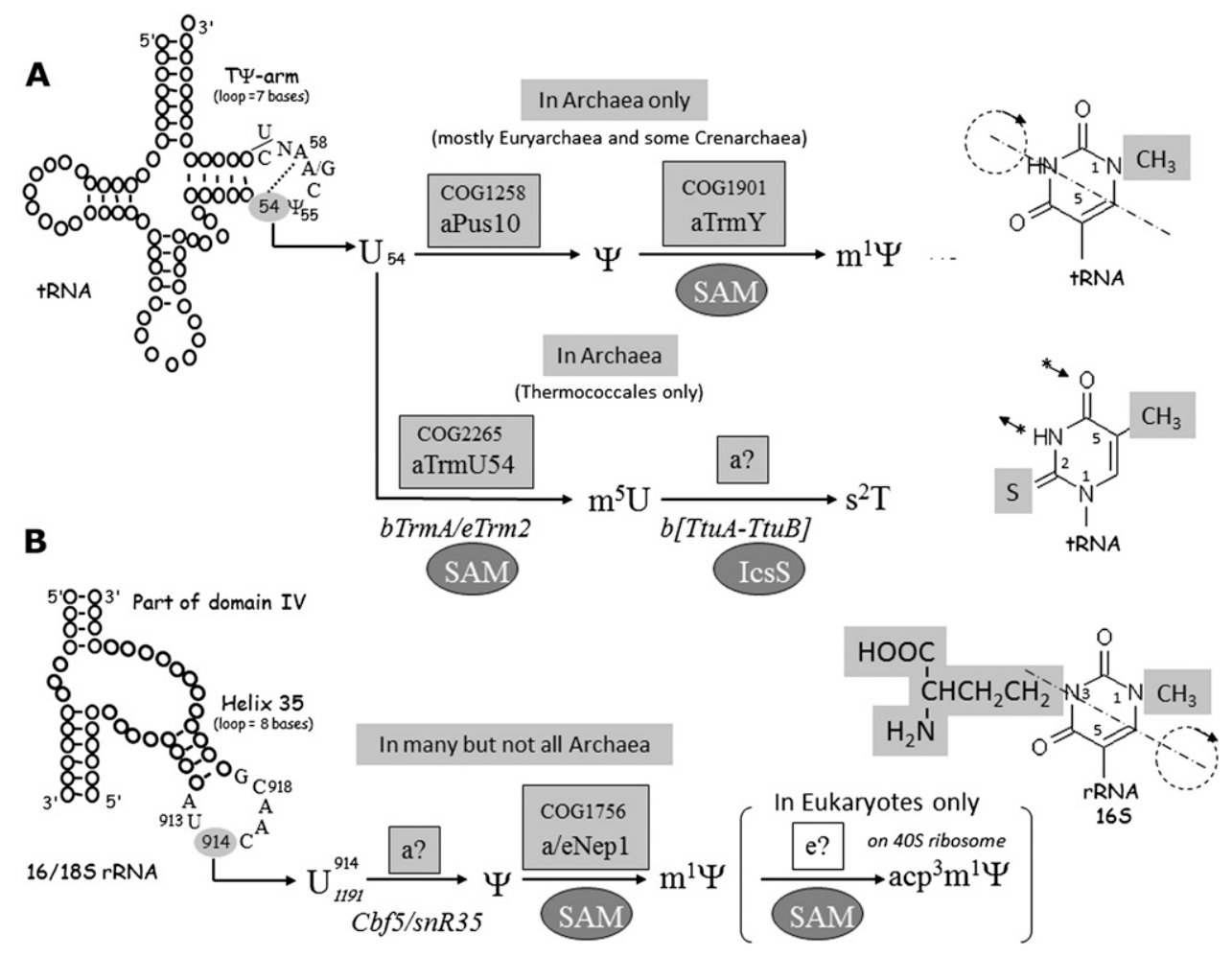

FIGURE 1. Enzymatic post-transcriptional modifications of selected uridines in RNA. (A) Schematic consensus of tRNA secondary structures indicating the U54 target within the highly conserved 7-nt T $\Psi$-loop. The dashed line indicates a reverse Hoogsteen base pair within the loop. In the majority of Archaea, U54 is first isomerized into $\Psi 54$ by a tRNA pseudouridine synthase, aPus10 (symbol "a" preceding the acronym of the enzyme denotes "archaeal," "b" means "bacterial," and "e" means "eukaryal"). In certain Archaea, $\Psi 54$ can be further methylated into ${ }^{1}{ }^{4}$ (54 by a SPOUTtype, SAM-dependent methyltransferase designated TrmY (this work). In Thermococcales, Bacteria, and Eukarya, U54 is methylated into $\mathrm{m}^{5} \mathrm{U} 54$ (riboT) by a distinct SAM-dependent tRNA-U54 methyltransferase aTrmU54, bTrmA, and eTrm2p, respectively. In thermophilic organisms, $\mathrm{m}^{5} \mathrm{U} 54$ can be further thiolated into $\mathrm{s}^{2} \mathrm{~m}^{5} \mathrm{U}\left(\mathrm{s}^{2} \mathrm{~T}\right)$ by the heteromeric enzyme TtuA/TtuB. (B) Schematic consensus of a portion of 16S rRNA as part of domain IV, encompassing the highly conserved 8-nt helix $35 \Psi$-loop. U914 in 16S rRNA of M. jannaschii, corresponding to U1191 in 18S rRNA of $S$. cerevisiae, is first isomerized into $\Psi$ by an archaeal enzyme (or enzymatic system) that remains to be identified. In S. cerevisiae this reaction is mediated by the snoRNP complex consisting of the pseudouridine synthase eCbf5 and snR35 guide RNA. The methylation of N1-atom of the uracil ring is further catalyzed by a SPOUT-type and SAM-dependent methyltransferase, Nep1 (also referred as Emg1). Only in some Eukarya (such as yeast, Drosophila, HeLa cells), is the $\mathrm{m}^{1} \Psi$ further hypermodified into a acp ${ }^{3} \mathrm{~m}^{1} \Psi$ derivative. On the right part of the figure are the different uridine derivatives. The dashed lines through the structure of $\mathrm{m}^{1} \Psi$ and $\mathrm{acp}^{3} \mathrm{~m}^{1} \Psi$ show the axis of base rotation during the isomerization process. The asterisks with small arrows indicate the atoms normally engaged in the reverse Hoogsteen base pair with A58. 
TABLE 1. Identification of $\mathrm{m}^{1} \Psi$ or $\mathrm{s}^{2} \mathrm{~T}\left(\mathrm{~s}^{2} \mathrm{~m}^{5} \mathrm{U}\right)$ in archaeal tRNAs

\begin{tabular}{|c|c|c|c|c|c|}
\hline \multicolumn{6}{|l|}{$\begin{array}{l}\text { KINGDOM } \\
\text { Phylum }\end{array}$} \\
\hline Organism & base & pus10 & $\operatorname{trm} Y$ & trmU54 & Reference \\
\hline \multicolumn{6}{|l|}{ EURYARCHAEOTA } \\
\hline \multicolumn{6}{|l|}{ Methanosarcinales } \\
\hline Methanococcoides burtonii & $\mathrm{m}^{1} \Psi$ & Yes & Yes & No & 1 \\
\hline Methanosarcina barkerii & $\mathrm{m}^{1} \Psi$ & Yes & Yes & No & 2 \\
\hline \multicolumn{6}{|l|}{ Archeoglobales } \\
\hline Archaeoglobus fulgidus & $m^{1} \Psi$ & Yes & Yes & No & 3 \\
\hline \multicolumn{6}{|l|}{ Thermoplasmatales } \\
\hline Thermoplasma acidophilum & $\Psi^{*}$ & Yes & No & No & $2,4,5$ \\
\hline \multicolumn{6}{|l|}{ Methanococcales } \\
\hline Methanococcus vannielii & $\mathrm{m}^{1} \Psi$ & Yes & Yes & No & 2,6 \\
\hline Methanococcus voltae & $m^{1} \Psi$ & Yes & Yes & No & 2 \\
\hline Methanocaldococcus jannaschii & $\mathrm{m}^{1} \Psi$ & Yes & Yes & No & This work \\
\hline Methanococcus igneus & $\mathrm{m}^{1} \Psi$ & nc & $\mathrm{nc}$ & $\mathrm{nc}$ & 1 \\
\hline \multicolumn{6}{|l|}{ Methanobacteriales } \\
\hline Methanothermus fervidus & $\mathrm{m}^{1} \Psi$ & $\mathrm{nc}$ & nc & $\mathrm{nc}$ & 3 \\
\hline Methanob.thermautotrophicum & $\Psi^{*}$ & Yes & No & No & 7 \\
\hline Methanobacterium bryantii & no $m^{7} \Psi$ & nc & $\mathrm{nc}$ & nc & 2 \\
\hline Methanobrevibacter smthii & no $m^{1} \Psi$ & Yes & No & No & 2 \\
\hline Methanomicrobium mobile & $\mathrm{m}^{1} \Psi$ & nc & $\mathrm{nc}$ & nc & 2 \\
\hline \multicolumn{6}{|l|}{ Halobacteriales } \\
\hline Haloferax volcanii & $m^{1} \Psi^{*}$ & Yes & Yes & No & $2,8,9$ \\
\hline Halococcus morrhuae & $\mathrm{m}^{1} \Psi^{*}$ & nc & $\mathrm{nc}$ & nc & $2,5,10$ \\
\hline Halobacterium cutirubrum & $m^{1} \Psi^{*}$ & $\mathrm{nc}$ & $\mathrm{nc}$ & $\mathrm{nc}$ & 11,12 \\
\hline \multicolumn{6}{|l|}{ Thermococcales } \\
\hline Pyrococcus abyssi & $\mathrm{s}^{2} \mathrm{~m}^{5} \mathrm{U}$ & Yes & Yes & Yes & 13 \\
\hline Pyrococcus furiosus & $\mathrm{s}^{2} \mathrm{~m}^{5} \mathrm{U}$ & Yes & Yes & Yes & 14,15 \\
\hline Thermococcus-isola MB4 & $\mathrm{s}^{2} \mathrm{~m}^{5} \mathrm{U}$ & Yes & Yes & Yes & 3 \\
\hline \multicolumn{6}{|l|}{ CRENARCHAEOTA } \\
\hline \multicolumn{6}{|l|}{ Desulfurococcales } \\
\hline Pyrodictium occultum & no $m^{1} \Psi$ & No & No & No & 3 \\
\hline Stetteria hydrogenophila & no $m^{1} \Psi$ & nc & $\mathrm{nc}$ & nc & 1 \\
\hline Thermodiscuss maritimus & no $m^{1} \Psi$ & $\mathrm{nc}$ & $\mathrm{nc}$ & $\mathrm{nc}$ & 3 \\
\hline \multicolumn{6}{|l|}{ Sulfolobales } \\
\hline Sulfolobus acidocaldarius & $U m^{*}$ & $\mathrm{No}^{\&}$ & No & No & 2,5 \\
\hline Sulfolobus solfataricus & no $m^{1} \Psi$ & $\mathrm{No}^{\&}$ & No & No & 3 \\
\hline Acidanus infernus & no $m^{1} \Psi$ & nc & $\mathrm{nc}$ & nc & 3 \\
\hline \multicolumn{6}{|l|}{ Thermoproteales } \\
\hline Pyrobaculum islandicum & $\mathrm{m}^{1} \Psi$ & Yes & Yes & No & 3 \\
\hline Thermoproteus neutrophilus & $\mathrm{m}^{1} \Psi$ & Yes & Yes & No & 3 \\
\hline
\end{tabular}

Purified bulk tRNAs were analyzed for their nucleoside content after complete digestion by nuclease, usually nuclease P1, followed by dephosphorylation and LC/MS or 2D-TLC after $5^{\prime}-{ }^{32} \mathrm{P}$ - post-labeling. An alternative TLC separation method used RNase T2-digests of uniformly labeled tRNAs isolated from ${ }^{32}$ P-labeled cells. The original LC-MS method is described in detail in Edmonds et al. (1985) and Crain (1990). For the ${ }^{32}$ P-post-labeling technique and TLC analysis, detailed information can be found in Grosjean et al. (2007). Analyses of uniformly labeled tRNAs can be found in Gupta and Woese (1980) and Gupta (1984). $\mathrm{m}^{1} \Psi, \mathrm{m}^{5} \mathrm{U}$, or $\mathrm{s}^{2} \mathrm{~T}$ have been found to date only at position 54 in tRNA. Their presence in bulk tRNA hydrolysates are therefore diagnostic of their presence at position 54 exclusively. Presence of $\Psi$ alone or Um, or any other $U$ derivatives at position 54 can be deduced only from direct tRNA sequencing (indicated in the table by an asterisk [*] next to the symbol of the modified nucleoside). The indication "no $\mathrm{m}^{1} \Psi^{\prime \prime}$ does not exclude the possibility of a nonmethylated $\Psi$ in the $T \Psi$-loop. Beside Um found in initiator tRNA Met sequenced from S. acidocaldarius, $\mathrm{s}^{2} \mathrm{U}$ and $\mathrm{s}^{2} U \mathrm{~m}$ were also found in bulk tRNA in some Crenarchaeota (Edmonds et al. 1991). Since no sequence analyses are available, this information was omitted from the table even if these modifications could be found at position 54 . The presence or absence of a gene coding for aPus10, aTrmY, and aTrmU54 was derived from the SEED database and from the taxonomic tool of Blink at NCBI. The italicized symbol Yes for TrmY of Thermococcales means that it is not certain whether the trmY gene is expressed and/or the gene product is functional, as no $\mathrm{m}^{1} \Psi$ was reported in tRNA of Thermococcales.

The "nc" symbol means "not applicable" because the genome sequence is not available. The " $\&$ " symbol refers to the fact that a gene coding for a Pus10 homolog is found in these genomes, but the corresponding proteins do not meet structural criteria for a functioning Pus10 (E Fitzek, R Gupta, and M Geisler, unpubl.). Names for Halobacterium cutirubrum have changed with time; Halobacterium salinarium, Halobacterium halobium are the same species. Halobacterium sp. NRC1, a different strain from H. cutirubrum, but with a sequenced genome was used to identify the presence of gene pus10, trmY, and trmU54. Numbers correspond to the following references: (1) (Noon et al. 2003); (2) (Gupta and Woese 1980), $\mathrm{m}^{1} \Psi$ is listed as $x \mathrm{U}$ in this reference; (3) (Edmonds et al. 1991); (4) (Kilpatrick and Walker 1981); (5) (Kuchino et al. 1982); (6) (Best 1978), $\mathrm{m}^{1} \Psi$ was misidentified as dihydrouridine in this reference, due to their similar mobilities in TLC; (7) (Gu et al. 1984); (8) (Gupta 1984); (9) (Gupta 1986); (10) (Pang et al. 1982); (11) (Gu et al. 1983); (12) (Nicoghosian et al. 1985); (13) (Urbonavicius et al. 2008); (14) (Constantinesco et al. 1999); (15) (Kowalak et al. 1994). 
Kowalak et al. 1994; Constantinesco et al. 1999). As previously noted (Gupta and Woese 1980; Pang et al. 1982), methyl groups on the uracil ring at tRNA position 54 in the two cases $\left(\mathrm{N} 1\right.$ in $\mathrm{m}^{1} \Psi$ and $\mathrm{C} 5$ in $\mathrm{m}^{5} \mathrm{U}$ ) bear similar orientations with respect to the ribose and the polynucleotide chain and both methylated products have similar shapes. This could be an example of evolutionary convergence of structures (and probably of function).

Only the first step in $\mathrm{m}^{1} \Psi$ formation in tRNA, the formation of $\Psi 54$, has been elucidated with the recent characterization of the tRNA- $\Psi 54$ synthase, Pus10 (Gurha and Gupta 2008). The enzyme responsible for the subsequent N1 methylation of the uracil ring of $\Psi 54$ and the corresponding gene has yet to be identified. However, experiments with whole-cell extract of $H$. volcanii incubated with ${ }^{32} \mathrm{P}$ radiolabeled T7-transcript and AdoMet (SAM) showed enzymatic formation of $\mathrm{m}^{1} \Psi 54$, indicating that the enzyme of interest was SAM dependent (Grosjean et al. 1995).

Nep1 (Nucleolar Essential Protein1, formerly named Emg1) from S. cerevisiae and Methanocaldococcus jannaschii was recently identified as a genuine SAM-dependent N1pseudouridine methyltransferase (Wurm et al. 2010). This enzyme belongs to Cluster of Orthologous Group (COG) 1756 (Tatusov et al. 2003) and converts $\Psi$ into $\mathrm{m}^{1} \Psi$ in small synthetic fragments of 8,9 , or 11 nucleotides in length (GAUUCAACGCC, where the second of the two adjacent Us is $\Psi$ ) (Wurm et al. 2010). This motif corresponds to the sequence in helix 35 of SSU rRNA of $S$. cerevisiae as well as of $M$. jannaschii, where Nep1 tightly binds (Buchhaupt et al. 2006). Nep1 is responsible for the methylation step in the formation of the hypermodified 1-methyl-3-(3-amino3-carboxypropyl) pseudouridine $\left(\mathrm{m}^{1} \mathrm{acp}^{3} \Psi\right)$ found at position 1191 in helix 35 of yeast 18S rRNA and also has a role in ribosome assembly (Fig. 1B; Meyer et al. 2011; Thomas et al. 2011). These functions appear to be conserved in other eukaryotes (Brand et al. 1978; Youvan and Hearst 1981). Despite the obvious sequence analogy of the Nep1 target with the conserved sequence GUUCAANC/U (underlined, cf. target sequences in Fig. 1, A and B) present in nearly all tRNAs sequenced so far (Marck and Grosjean 2002), Nep1 is certainly not the missing tRNA N1-pseudouridine methyltransferase. The reasons are: (1) The genome of $S$. acidocaldarius contains a Nep1 homolog (Saci_0034), but its bulk tRNA lacks $\mathrm{m}^{1} \Psi$, and its only sequenced tRNA harbors $\mathrm{U}_{\mathrm{m}} 54$ (Table 1; Gupta and Woese 1980; Kuchino et al. 1982); (2) conversely, the genome of $H$. volcanii lacks the gene coding for Nep1, while nearly all of its tRNAs harbor $\mathrm{m}^{1} \Psi 54$ (Table 1; Gupta 1984, 1986); (3) this absence is consistent with the fact that helix 35 of $H$. volcanii $16 \mathrm{~S}$ rRNA harbors an $\operatorname{acp}^{3} U$ and not the "hypermodified" $\mathrm{m}^{1} \mathrm{acp}^{3} \Psi$ as in eukaryotes (Kowalak et al. 2000).

A better candidate for the missing $\mathrm{m}^{1} \Psi 54$ methyltransferase came from a bioinformatics analysis of a large variety of orphan genes coding for putative AdoMet-dependent methyltransferases in genomes of microorganisms belong- ing to the three domains of life. This analysis identified one of the methyltransferases belonging to COG1901, encompassing an $\alpha / \beta$ knot fold (also named SPOUT) superfamily of methyltransferases as a valid candidate (Tkaczuk et al. 2007). This prediction fits with the observation that genes of this family usually cluster with pus10 in several archaeal genomes (Grosjean et al. 2008a). Lastly, the crystal structure of a COG1901 family member, Mj1640 from $M$. jannaschii, was solved in complex with AdoMet at $1.4 \AA$ resolution (Chen and Yuan 2010). Mj1640 protein shares much structural similarity with the highly conserved eukaryotic nucleolar Emg1/Nep1 protein at its C-terminal half containing the conserved deep trefoil knot fold (Z-score 15.7, RMS $2.5 \AA, 163 \mathrm{C} \alpha$ ). However, because of significant differences in N-terminal extension domain and overall surface charge distribution, it was suggested that the two proteins Nep1 and Mj1640 target different RNA sequences (Chen and Yuan 2010). This structural data greatly strengthened the prediction that the COG1901 (or DUF358) RNA methylase family was the missing tRNA- ${ }^{1} \Psi$ forming enzyme, and we set out to test this experimentally using both in vivo and in vitro assays. Here we show that a $H$. volcanii strain deleted in the COG1901 family gene HVO_1989 lacks $\mathrm{m}^{1} \Psi$ in tRNA, and that in vitro Mj1640 catalyzes the formation of $\mathrm{m}^{1} \Psi$ at position 54 on tRNA. These results led to the renaming of the Archaeal COG1901 proteins as TrmY (as $\mathrm{Y}$ is commonly used to represent $\Psi$ ) for tRNA(pseudouridine54-N1)-methyltransferase.

\section{RESULTS}

\section{trmY is not essential in $H$. volcanii, but deletion of trm $Y$ leads to the absence of $\mathrm{m}^{1} \Psi 54$ in $H$. volcanii tRNA}

The H. volcanii trmY (COG1901 homolog, HVO_1989) was deleted using previously published methods (Allers et al. 2004). Deletion of trm $Y$ in this strain (VDC2376) was confirmed by PCR using two primer pairs, one designed to anneal outside the deleted fragment and the other within (Fig. 2A). trm $Y$ is therefore dispensable in $H$. volcanii. Deletion of trm $Y$ did not lead to any obvious phenotype when analyzing growth in rich or minimal liquid medium or on solid medium at $20,30,37,44$, and $50^{\circ} \mathrm{C}$ or with total salt concentrations ranging from $12 \%(1.812 \mathrm{M} \mathrm{NaCl}$, $65.28 \mathrm{mM} \mathrm{MgCl}_{2}, 63 \mathrm{mM} \mathrm{MgSO}_{4}$, and $\left.41.64 \mathrm{mM} \mathrm{KCl}\right)$ to 25\% (3.775 M NaCl, $136 \mathrm{mM} \mathrm{MgCl}, 131.25 \mathrm{mM} \mathrm{MgSO}_{4}$, and $86.75 \mathrm{mM} \mathrm{KCl}$ ) (compared with the standard YPC media with a final concentration of $18 \%$ salt; data not shown). To test whether TrmY was involved in $\mathrm{m}^{1} \Psi$ formation, we first extracted bulk tRNA from VDC2376 $(\Delta t r m Y)$ and H26 (the isogenic parent strain as wild type [WT]). The bulk tRNA preparations were enzymatically hydrolyzed with nuclease P1 and snake venom phosphodiesterase and dephosphorylated with alkaline phosphatase, 

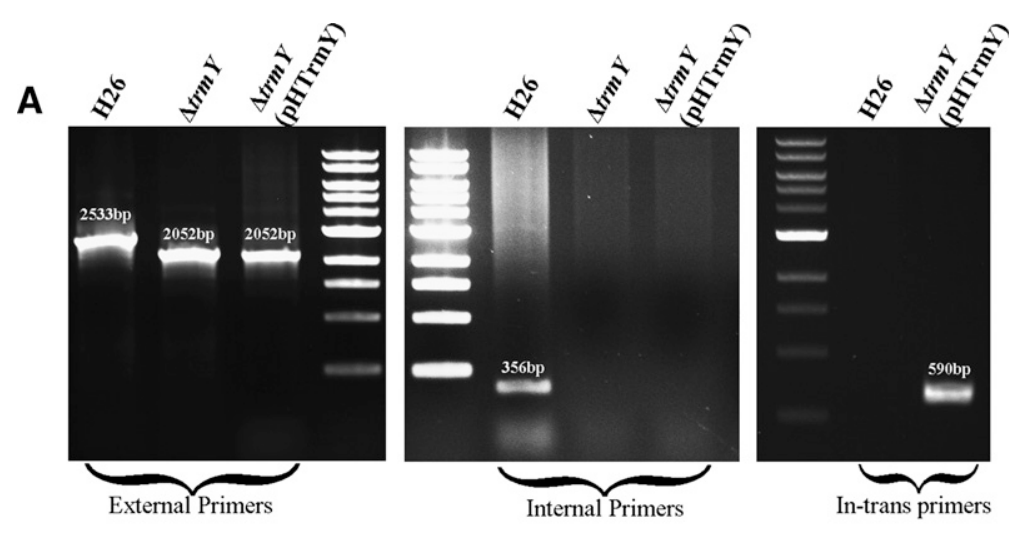

B
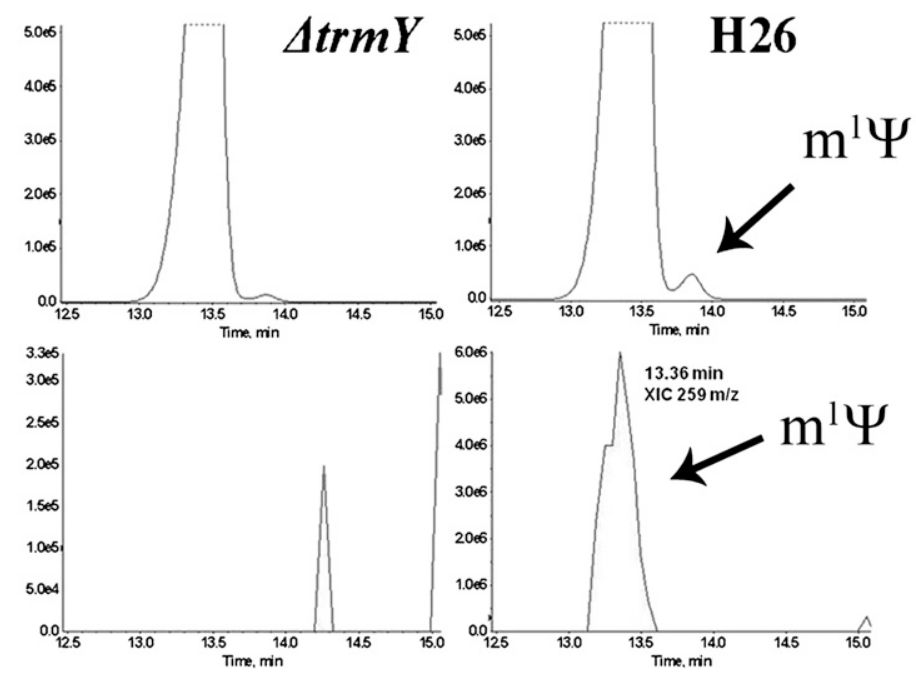

FIGURE 2. Construction and phenotype of the trmY-deleted strain of $H$. volcanii. $(A)$ Deletion of the trmY gene was confirmed by PCR; (left) PCR products using primers designed to anneal outside the gene (HvO_1989_Ext_F and HvO_1989_Ext_R) confirm a genomic rearrangement of correctly predicted sizes in WT and mutant strains; (middle) PCR products using primers designed to anneal within the target gene (HvO_1989_Int_F and HvO_1989_Int_R) show the absence of the $\operatorname{trm} Y$ internal segment in the mutant and its presence in the WT strain; (right). To confirm the presence of VNG_1980c in trans, primers were designed to anneal to the complementing gene (HsaI_COG1901_Fwd and HsaI_ COG1901_Rev). The predicted size of the fragment is observed in the rescued strain. $(B)$ LC-MS/MS analysis of tRNA extracted from H26 (wild-type) and VDC2376 ( $\Delta$ trmY) showing the UV trace at $254 \mathrm{~nm}(t o p)$. The $259 \mathrm{~m} / z$ ion that corresponds to the protonated molecular weight $\left(\mathrm{MH}^{+}\right)$of $\mathrm{m}^{1} \Psi$ was detected by MS at $13.36 \mathrm{~min}$ in the WT background, while no 259 $\mathrm{m} / \mathrm{z}$ ion was detected in the $\Delta$ trmY strain (bottom).

and the ribonucleosides analyzed by LC/MS-MS as described previously (de Crécy-Lagard et al. 2010). The 259 $\mathrm{m} / \mathrm{z}$ ion that corresponds to the protonated molecular weight $\left(\mathrm{MH}^{+}\right)$of $\mathrm{m}^{1} \Psi$ was detected by MS at $13.36 \mathrm{~min}$ in the WT background, while no $259 \mathrm{~m} / \mathrm{z}$ ion was detected in the $\Delta t r m Y$ strain (Fig. 2B). The peak observed in the mutant strain and not in the WT strain between 14 and 14.5 min corresponds to background (see the differences in the intensity scales between the right and left panels). As in our set-up, the $\mathrm{m}^{1} \Psi$ peak eluted as a trail of the $U$ peak at 13-13.6 min and these two peaks were difficult to separate with a trailing peak most certainly corresponding to an unidentified modification remaining in the mutant strain, a two-dimensional thin layer chromatography (2D-TLC) method was used to better detect the $\mathrm{m}^{1} \Psi$ modification. Also, to rescue the effects of the trm $Y$ deletion, a derivative of the $\Delta \operatorname{trm} Y$ strain was created (VDC2604), which contained a plasmid-borne copy of the COG1901 encoding gene from Halobacterium sp. NRC1, VNG_1980C (Fig. 2A). The WT, $\Delta$ trmY (VDC2376), and $\Delta$ trmY + pHTrmY (VDC2604) strains were in vivo labeled with ${ }^{32} \mathrm{P}$. Total tRNA was isolated, digested by nuclease $\mathrm{P} 1$, and resolved by $2 \mathrm{D}-\mathrm{TLC}$. As shown in Figure $3 \mathrm{~A}$, radioactive $\mathrm{m}^{1} \Psi$ spot is present in both WT and complemented strains but is absent from the $\Delta$ trm $Y$ strain (VDC2376). Because $\mathrm{m}^{1} \Psi$ is present only at position 54 in $H$. volcanii tRNAs (Gupta 1984, 1986), these results show that, at least in halophilic Archaea, COG1901 proteins (TrmY) are required for the formation of $\mathrm{m}^{1} \Psi 54$ in tRNA.

Lack of TrmY in the $\Delta \operatorname{trm} Y$ strain only affects methylation and not $\Psi$ formation at position 54 of the tRNA. We used CMCT-primer extension reactions, which specifically allow the identification of $\Psi$ at a particular position in RNA (Bakin and Ofengand 1998) to determine the presence of $\Psi 54$ in $\Delta$ trm $Y$ strain. As seen in Figure 3B, the $\Psi$-specific band (marked by an arrow) is present at position 54 of tRNA in the $\Delta \operatorname{trm} Y$ strain, but not in the $\mathrm{WT}$ and complemented strains, as expected if $\mathrm{m}^{1} \Psi 54$ and not $\Psi 54$ is present in these last two strains. As expected, $\Psi 55$-specific bands are present in all three strains. These results suggested that Pus10-mediated $\Psi 54$ (and $\Psi 55)$ formation does not require the presence of TrmY activity.

\section{M. jannaschii TrmY catalyzes the formation of $m^{1} \Psi 54$ in tRNA in vitro}

The $\left[\alpha-{ }^{32} \mathrm{P}\right]$ UTP-labeled tRNA ${ }^{\text {Trp }}$ substrate, generated by transcription of a plasmid carrying a synthetic $H$. volcanii tRNA $^{\text {Trp }}$ lacking its intron, was first modified by purified recombinant $M$. jannaschii Pus10, thus converting $\mathrm{U}$ at both positions 54 and 55 to $\Psi$, as described before (Gurha and Gupta 2008). This in vitro pseudouridylated tRNA ${ }^{\operatorname{Trp}}$ was used as a substrate for further enzymatic methylation by the recombinant $M$. jannaschii TrmY protein mostly 
A
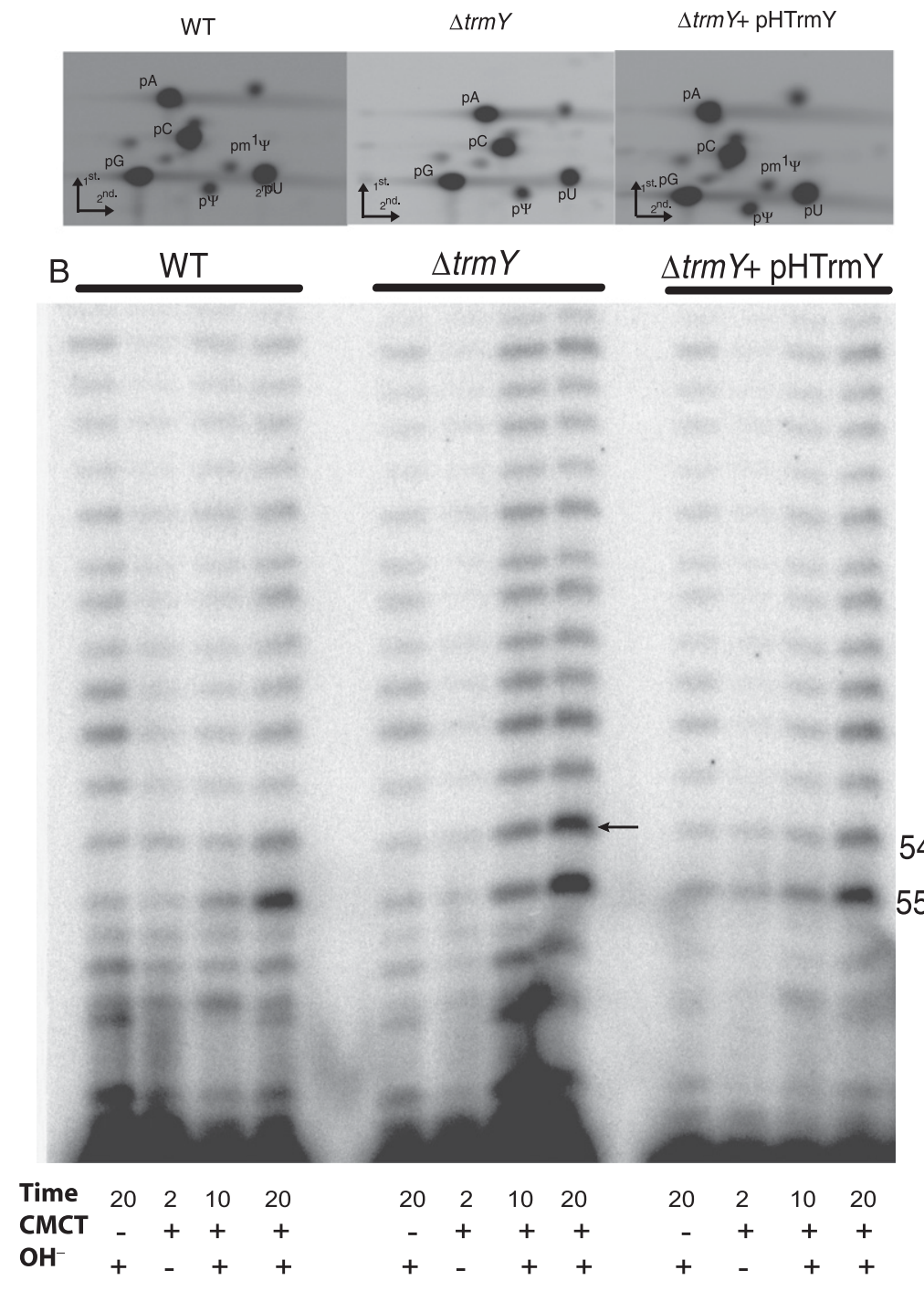

FIGURE 3. Formation of $\mathrm{m}^{1} \Psi$ of $H$. volcanii tRNA is mediated by TrmY. (A) Nuclease P1 digests of uniformly labeled tRNAs were resolved by $2 \mathrm{D}-\mathrm{TLC}$. $\mathrm{pA}, \mathrm{pC}, \mathrm{pG}, \mathrm{pU}, \mathrm{p} \Psi$, and $\mathrm{pm}^{1} \Psi$ indicate $5^{\prime}$-phosphorylated $\mathrm{A}, \mathrm{C}, \mathrm{G}, \mathrm{U}, \Psi$, and $\mathrm{m}^{1} \Psi$, respectively. The radioactive spot corresponding to $\operatorname{pm}^{1} \Psi$ is present in both wild-type (H26) and complemented $(\Delta t r m Y+\mathrm{pHTrmY})$ strains, but is absent from $\Delta$ trmY strain (middle). (B) CMCT-primer extension analyses to determine the modification status of residue at position 54 of $H$. volcanii elongator tRNA ${ }^{\text {Met }}$ were done using primer Met-CCA2 (position marked in Fig. 4A) and total small RNA of wild-type, $\Delta \operatorname{trm} Y$, and $\Delta \operatorname{trm} Y+\mathrm{pHTrmY}$ strains. RNAs were treated with $(+)$ or without (-) CMCT for the indicated time (in minutes), followed by alkali (OH-) treatment $(+)$ or no treatment $(-)$. Positions of tRNA residues 54 and 55 are marked on the side. A dark band in CMCT followed by alkali treatment lanes, with an increased intensity in the 20-min treatment lane, indicates the presence of $\Psi$ at that position. These reactions show that unmethylated $\Psi$ s are present at position 55 in all three strains, but at position 54 only in the $\Delta$ trm $Y$ strain (the band is marked by an arrow).

prepared under renaturing conditions. The doubly modified RNA was then phenol extracted, digested with nuclease $\mathrm{P} 1$, and the resulting digested products analyzed by $2 \mathrm{D}-$ TLC. Autoradiographies of the TLC plates revealed the presence of a radiolabeled spot corresponding to $\mathrm{pm}^{1} \Psi$ only when the tRNA ${ }^{\text {Trp }}$ transcript was first incubated with Pus10 and then with TrmY (Fig. 4B). When tRNA ${ }^{\text {Trp }}$ was treated with TrmY without pretreatment with Pus10 it did not show any $\mathrm{pm}^{1} \Psi$ (data not shown). Nearest neighbor analyses using RNase T2 digestion on the same radiolabeled tRNA samples confirmed the presence of $\mathrm{m}^{1} \Psi \mathrm{p}$ only in the tRNA ${ }^{\text {Trp }}$ incubated with both Pus10 and TrmY (Fig. 4C), attesting that within tRNA ${ }^{\operatorname{Trp}}$ the $\mathrm{m}^{1} \Psi$ residue was located on the $5^{\prime}$ side of a ${ }^{32} \mathrm{P}$ labeled-uridine residue. RNase T2 produces ribonucleotide 3 '-monophosphates $(\mathrm{Np})$, and in the process transfers labeled phosphate on the $5^{\prime}$ side of a residue in the RNA to the $3^{\prime}$ side of the preceding residue. In $H$. volcanii tRNA $^{\text {Trp }}$ there is only one $U$ residue (position 54) that precedes another $\mathrm{U}$ residue (position 55) (see Fig. 4A). Therefore, the $\mathrm{m}^{1} \Psi \mathrm{p}$ observed in Figure $4 \mathrm{C}$ is obviously derived from the residue at position 54 of this RNA. Moreover, $\Psi \mathrm{p}$ is absent in the rightmost panel of Figure 4C, indicating that the methylation reaction was nearly complete under our experimental conditions, i.e., all $\Psi 54$ being converted into $\mathrm{m}^{1} \Psi 54$. This methylation is AdoMet dependent, as it was not observed when AdoMet was omitted from the reaction mixture (data not shown). Similar methylations were obtained when $H$. volcanii elongator tRNA ${ }^{\text {Met }}$ was used as substrate (Fig. 4D) instead of $H$. volcanii tRNA $^{\text {Trp. This tRNA }}{ }^{\text {Met }}$ contains residues G58 and G60 instead of the conserved A58 and semiconserved pyrimidine60 at these positions of the $\mathrm{T} \Psi$-loop (Fig. 4A).

Initial methylation reactions were done using proteins prepared under native conditions. However, additional AdoMet was not needed for methylation with this protein when the protein was in excess of the RNA. AdoMet had to be added to the reaction for complete conversion of $\Psi 54$ to $\mathrm{m}^{1} \Psi 54$ when the RNA was equal to or in molar excess of this protein. This was not unexpected, because the protein prepared under native conditions contains bound AdoMet (Chen and Yuan 2010). Furthermore, methylation by AdoMet-containing TrmY (under excess enzyme concentration) could be inhibited by addition of S-adenosylhomocysteine, an inhibitor of SAM-dependent methyltransferases (data not shown). Similarity of results using 
A

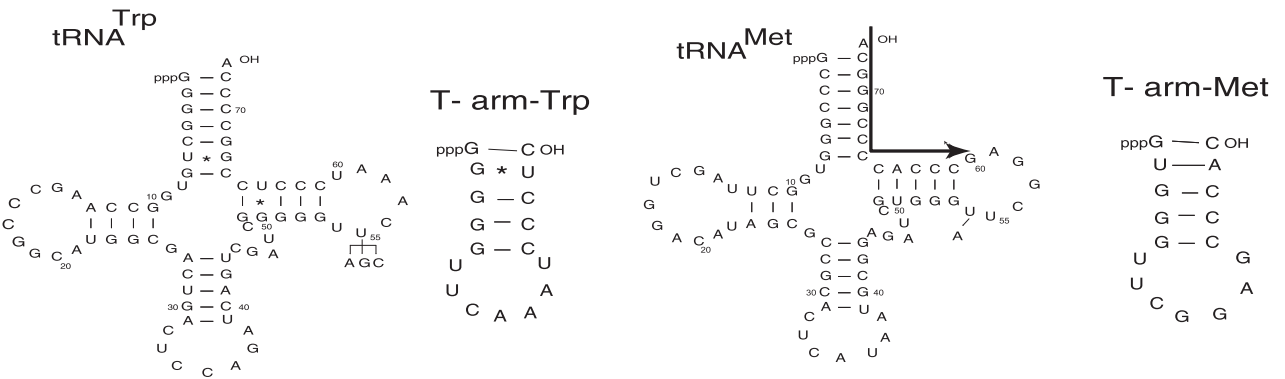

B
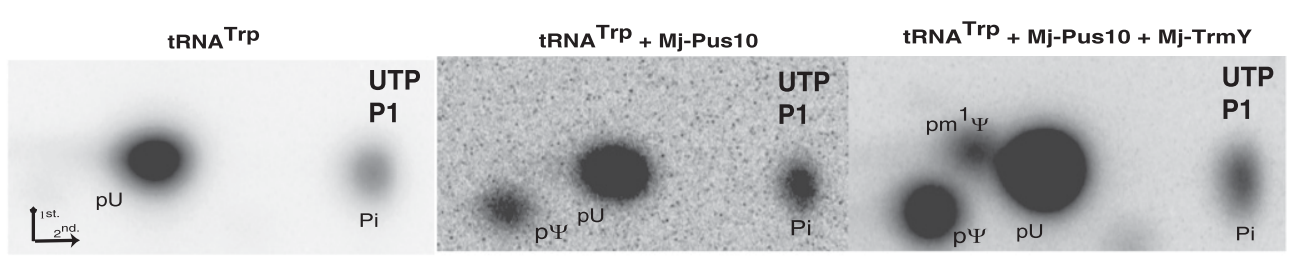

C

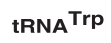

tRNA ${ }^{\text {Trp }}+$ Mj-Pus10

tRNA ${ }^{\text {Trp }}+$ Mj-Pus10 + Mj-TrmY

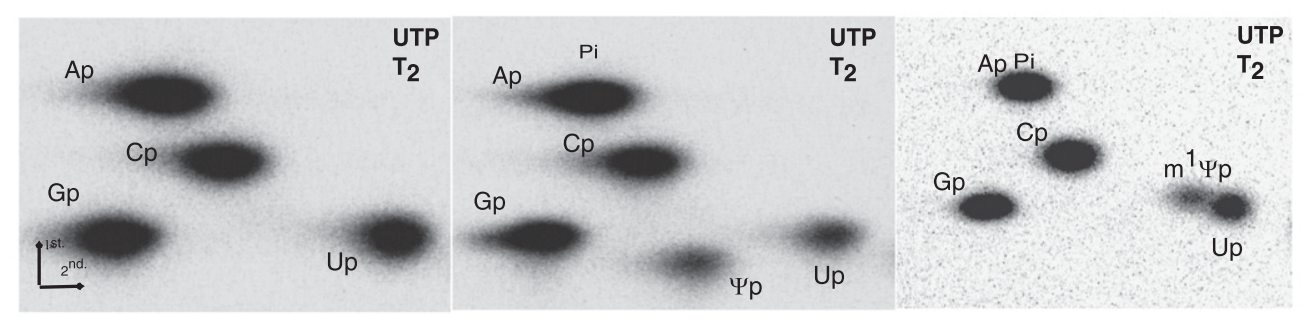

D

tRNA ${ }^{\text {Met }}$

tRNA ${ }^{\text {Met }}+$ Mj-Pus10

tRNA Met + Mj-Pus10 + Mj-TrmY

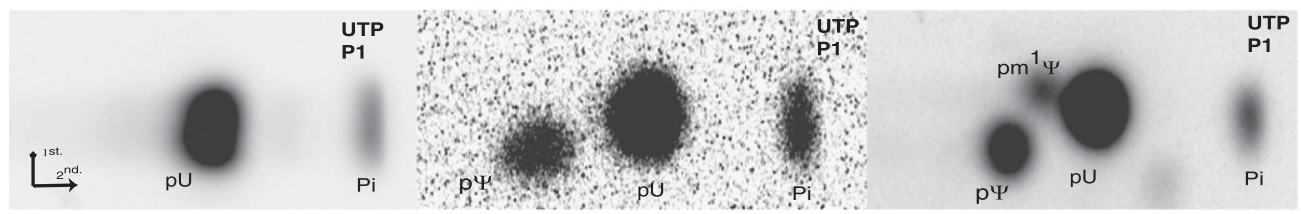

E

tRNATrp + Mj-Pus10 + Mj-TrmY

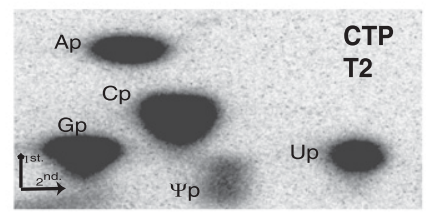

F

T-arm-Trp + Mj-Pus10 + Mj-TrmY

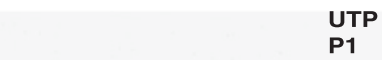

G

H

I

tRNATrp-U55A + Mj-Pus10 + Mj-TrmY tRNATrp-U55G + Mj-Pus10 + Mj-TrmY tRNATrP-U55C + Mj-Pus10 + Mj-TrmY
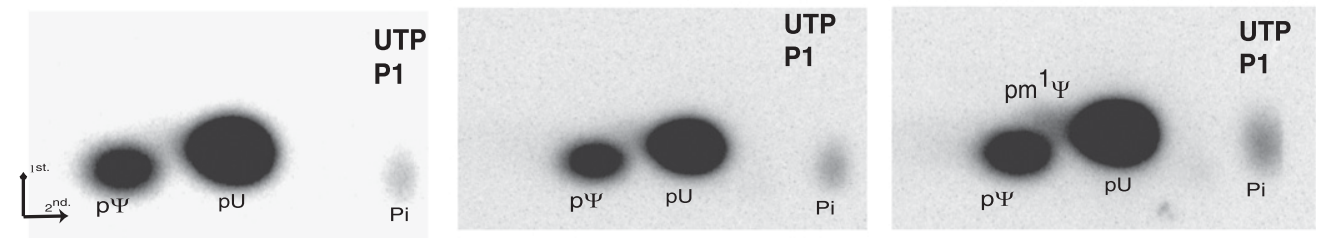

FIGURE 4. M. jannaschii TrmY can convert $\Psi 54$ of tRNA to $\mathrm{m}^{1} \Psi 54$. (A) Sequences of transcripts used in the reactions. Mutations changing U55 of tRNA ${ }^{\text {Trp }}$ and U54 of tRNA ${ }^{\text {Met }}$ are indicated. The arrow in tRNAMET sequence indicates the position of primer Met-CCA2 used for CMCTprimer extension analyses shown in Figure 3B. $(B, C)\left[\alpha-{ }^{32} \mathrm{P}\right] \mathrm{UTP}$-labeled tRNA ${ }^{\text {Trp }}$ was first pseudouridylated by $M$. jannaschii Pus10 (Mj-Pus10) and then methylated by M. jannaschii TrmY (Mj-TrmY) as described in Materials and Methods. Nuclease P1 or RNase T2 (indicated in panels) digests of purified products were resolved by 2D-TLC on cellulose plates. "p" before or after a nucleoside letter indicates the $5^{\prime}$ or 3 ' phosphate of that nucleoside. (Pi) inorganic phosphate. $(D)$ Treatments similar to those in $B$ using $\left[\alpha{ }^{32} \mathrm{P}\right] \mathrm{UTP}-\mathrm{labeled}$ tRNA ${ }^{\mathrm{Met}}$ as substrate. The middle panel here (and in $B$ ) is shown to indicate that $\Psi$ in the tRNA is produced by Mj-Pus10. (E) TLC separation of RNase T2 digest of $\left[\alpha-{ }^{32} \mathrm{P}\right] \mathrm{CTP}-\mathrm{labeled}$ tRNA $^{\text {Trp }}$ following treatment with Mj-TrmY. $(F-I)$ TLC separation of nuclease P1 digests of $\left[\alpha-{ }^{32} \mathrm{P}\right] \mathrm{UTP}-$ labeled T-arm-Trp, mutant tRNA ${ }^{\text {Trp }}$ U55A, tRNA ${ }^{\text {Trp }}-$ U55G, and tRNA ${ }^{\text {Trp }}-$ U55C, respectively (indicated in the panels), following treatment with Mj-TrmY. 
proteins prepared under native and renaturing conditions suggested that AdoMet is not required for the stability of the recombinant protein.

M. jannaschii TrmY converts only tRNA $\Psi 54$ and not $\Psi 55$ to $\mathrm{m}^{1} \Psi$. This is shown by TLC analyses of RNase T2 digestion of $\left[\alpha-{ }^{32} \mathrm{P}\right] \mathrm{CTP}$-labeled $\mathrm{tRNA}^{\text {Trp }}$ first incubated with Pus10 then with TrmY (Fig. 4E). Autoradiography of the TLC plate reveals the presence of labeled $\Psi \mathrm{p}$ and the absence of $\mathrm{m}^{1} \Psi \mathrm{p}$, indicating that $\Psi 55$ (preceding C56) is not converted to $\mathrm{m}^{1} \Psi$ in this tRNA.

\section{M. jannaschii TrmY can produce $m^{1} \Psi$ in just

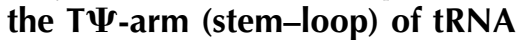

Previously it was shown that $M$. jannaschii Pus10 can produce $\Psi$ in the T-arm-Trp (Fig. 4A), a 17-base fragment of $\mathrm{tRNA}^{\mathrm{Trp}}$, at positions that correspond to positions 54 and 55 of tRNA (Gurha and Gupta 2008). The same pseudouridylated fragment and the equivalent fragment from tRNA ${ }^{\text {Met }}$ (Fig. 4A) are both substrates for the $M$. jannaschii TrmY (Fig. 4F; data not shown). Methylation of $\Psi$ in Pus10-treated T-arm-Trp occurs only at positions equivalent to 54 and not 55 of the tRNA (data not shown).

\section{M. jannaschii TrmY requires $\Psi 55$ (or possibly U55) in the tRNA to produce $\mathrm{m}^{\mathbf{1}} \Psi 54$}

In a mutant tRNA ${ }^{\mathrm{Trp}}$, where $\mathrm{U} 55$ is changed to any other residue (C, A, or $\mathrm{G}$ ), the $\mathrm{U} 54$ can still be converted to $\Psi 54$ by M. jannaschii Pus10 (Gurha and Gupta 2008). However, $\Psi 54$ of a mutant tRNA ${ }^{\text {Trp }}$, where the U55 is changed to A55 (Fig. 4A), is not a substrate for M. jannaschii TrmY. Nuclease P1 digest of $\left[\alpha-{ }^{32} \mathrm{P}\right] \mathrm{UTP}$-labeled transcript of this mutant tRNA does not show any $\mathrm{pm}^{1} \Psi$ after treatment with TrmY (Fig. 4G). Similarly, a U-to-G change at position 55 did not lead to any $\mathrm{m}^{1} \Psi$ formation (Fig. $4 \mathrm{H}$ ), while a trace amount of $\mathrm{pm}^{1} \Psi$ was observed when U55 was changed to C55 (Fig. 4I). These experiments suggest that the presence of $\Psi 55$ (or possibly U55) in the tRNA is required for enzymatic methylation of the adjacent $\Psi 54$ by $\operatorname{TrmY}$ to produce $\mathrm{m}^{1} \Psi 54$. However, at present we cannot distinguish whether an unmodified U55 can substitute for the requirement of $\Psi 55$, because Pus10 treatment of RNA converts both U54 and U55 in our substrates to $\Psi$ (Gurha and Gupta 2008).

\section{DISCUSSION}

In the present work, by combining genetic and biochemical experiments, we showed that in at least two Euryarchaeota, $H$. volcanii, and M. jannaschii COG1901, genes encode the missing tRNA(pseudouridine54-N1)-methyltransferase or TrmY. This newly identified TrmY enzyme belongs to the SAM-dependent SPOUT super family of dimeric enzymes (Tkaczuk et al. 2007). The closest COG1901 homologs among SPOUT methyltransferase of known catalytic func- tion is the newly identified dimeric Nep1 (COG1756) catalyzing the N1-methylation of $\Psi\left(\mathrm{m}^{1} \Psi\right)$ in helix 35 of $18 \mathrm{~S}$ rRNA of Eukarya and Archaea (Fig. 1B; Wurm et al. 2010). Hence, these two families represent yet another example of two closely related SPOUT subfamilies that target different RNA molecules (an rRNA and a tRNA).

M. jannaschii TrmY can produce $\mathrm{m}^{1} \Psi 54$ in full-sized tRNAs as well as at the equivalent position in T $\Psi$-stemloop substrates (17-mer T $\Psi$-arm of tRNA). Likewise, the tRNA: ${ }^{5} \mathrm{U} 54$ methyltransferases of $E$. coli (TrmA or RumT), of S. cerevisiae (Trm2p), and of P. abyssi (PAB_0719, aTrmU54) can produce $\mathrm{m}^{5} \mathrm{U} 54$ in similar full-sized or truncated RNAs (Gu et al. 1996; Becker et al. 1997; Urbonavicius et al. 2008), suggesting a possibility of similar substrate recognition modes as described for E. coli TrmA (Alian et al. 2008) and archaeal TrmU54 (Walbott et al. 2008). However, archaeal TrmY can methylate $\Psi 54$ in tRNA harboring G58 and G60 (Fig. 4A,D). This differs from the yeast $\operatorname{Trm} 2 \mathrm{p}$ enzyme, which requires the presence of both A58 and a pyrimidine at position 60 to methylate its substrate (Becker et al. 1997). This specificity of yeast Trm $2 p$ probably depends on the formation of a reverse intra-loop Hoogsteen pair between U54 and A58 in the tRNAs (Becker et al. 1997). The M. jannaschii TrmY requires a $\Psi$ (or possibly a $U$ ) at position 55 to efficiently methylate $\Psi 54$. This is reminiscent of the requirements of the yeast Trm2p enzyme, where U55 cannot be replaced by any other residue (Becker et al. 1997). We could not determine whether the residue $3^{\prime}$ adjacent to the target $\Psi$ residue needs to be $\Psi$ or an unmodified $U$ because of our experimental design, but in the case of the archaeal Nep1, it was shown that the $5^{\prime}$ adjacent residue to the target $\Psi$ residue can be an unmodified U (Wurm et al. 2010).

In addition to M. jannaschii TrmY, high-resolution crystal structures of other SAM-dependent RNA methyltransferases, such as Nep1 of $M$. jannaschii and S. cerevisiae, TrmA and RumA both of E. coli, are known (Lee et al. 2005; Alian et al. 2008; Leulliot et al. 2008; Taylor et al. 2008; Thomas et al. 2011). Nep1 is an rRNA N1- $\Psi$ methyltransferase, TrmA is a tRNA C $5-\mathrm{m}^{5} \mathrm{U}$ methyltransferase, whereas RumA is an rRNA C5- $\mathrm{m}^{5} \mathrm{U}$ methyltransferase. Structural analysis of these RNA methyltransferases reveals that TrmY and Nep1 belong to SPOUT family, whereas TrmA and RumA belong to Rossmann $(\alpha / \beta)$ fold. These two groups share fewer structural similarities, except for a somehow similar $\alpha / \beta$ fold for AdoMet and RNA substrate binding. Although TrmY and Nep1 share the same characteristic deep trefoil knot core, different structural domains/motifs extended from the deep trefoil knot core are observed. These extra domains/motifs are proposed to facilitate RNA substrate binding and/or selection. Similarly, TrmA and RumA share close structural similarity both in RNA binding and catalytic domains. However, significant structural differences of the extended loop linking the RNA-binding domain and the catalytic domain 
are observed, suggesting the functional role of this loop in substrate selection.

TrmY homologs are found in the majority of Euryarchaeota and in a few Crenoarchaeota. All Archaea that contain a TrmY homolog contain a Pus10 homolog (see the COG1901 Subsystem in the SEED database; http://pubseed.theseed.org/ SubsysEditor.cgi? page $=$ SubsystemOverview) consistent with our finding that the presence of $\Psi$ at position 54 is a prerequisite to the formation of $\mathrm{m}^{1} \Psi$. The presence or absence of $m^{1} \Psi$ in archaeal tRNAs has been reported by different research groups over many years (Table 1). The presence of $\Psi$ or $\mathrm{m}^{1} \Psi$ correlates well with the presence and absence of Pus10 and TrmY, with the exception of the Thermococcales (Table 1). Despite the presence of both pus10 and trmY genes in their genomes (Table 1) (COG1901 Subsystem in the SEED database), $\mathrm{m}^{5} \mathrm{U}$ or $\mathrm{s}^{2} \mathrm{~T}$ and not $\mathrm{m}^{1} \Psi$ were formally identified in bulk tRNAs from Thermococcales (Fig. 1A; Table 1). Likewise, when a tRNA transcript specific for Phe, Asp, or Ile, lacking modifications, was incubated with AdoMet and cell extracts from $P$. furiosus or P. abyssi, $\mathrm{m}^{5} \mathrm{U}$ was almost quantitatively formed at position 54 of the $\mathrm{T} \Psi$-loop (Constantinesco et al. 1999; Urbonavicius et al. 2008). Under the same experimental conditions, U54 in the tRNA ${ }^{\text {Ile }}$ transcript was shown to be "doubly" modified into $\mathrm{m}^{1} \Psi$ when incubated with cell extracts from $H$. volcanii (Grosjean et al. 1995). The enzyme responsible for the formation of $\mathrm{m}^{5} \mathrm{U} 54$ in $P$. abyssi was recently identified as PAB_0719 (aTrmU54) (Urbonavicius et al. 2008; Auxilien et al. 2011). This protein is a member of the COG2265 SAM-dependent, Rossmannlike RNA ${ }^{5} \mathrm{U}$ methyltransferase family. Phylogenetic analysis showed that it has been acquired by lateral gene transfer of a bacterial RlmD gene responsible for the site-specific formation of $\mathrm{m}^{5} \mathrm{U}$ in $23 \mathrm{~S}$ rRNA (position 1939 in E. coli). Thus, during evolution, the RlmD-like protein in P. abyssi (PAB_0719, aTrmU54) has changed target specificity from rRNA to tRNA. The question of the role of TrmY proteins in Thermococcales remains open. Are these still active as a tRNA ${ }^{1} \Psi$ methyltransferase, but in specific conditions that have escaped detection, or have they acquired another function? Further experimental work is required to address this issue.

Only a few sequenced Crenarchaeota encode both genes pus10 and trmY (COG1901 subsystem in the SEED database), these include Ignococcus hospitalis KIN4_1, Aeroyrum pernix K1, the Pyrobaculum species, and a few other (but not all) Thermoproteales. Indeed, $\mathrm{m}^{1} \Psi 54$ was detected in bulk tRNAs extracted from two thermoproteales (Pyrobaculum islandicum and Thermoproteus neutrophilus) fitting with the genomic data (Table 1). The only other experimental data available for a Crenarchaeota is for S. acidocaldarius, where $2^{\prime}$-O-methyluridine at tRNA position 54 (Um54) was identified (Gupta and Woese 1980; Kuchino et al. 1982), there again fitting with the absence of both active Pus10 proteins and TrmY in Sulfolobales (Table 1).
While COG1901 is primarily found in Archaea, homologs are surprisingly found in most sequenced Vibrio genomes, in two Shewanella baltica strains (OS195 and OS185), two Photobacterium profundum strains (SS9 and 3TCK) and in Alcanivorax borkumensis SK2 (Fig. 5A) (COG1901 subsystem in the SEED database). $\mathrm{m}^{1} \Psi 54$ is typically an archaeal tRNA signature modification (Gupta and Woese 1980; Pang et al. 1982) and has never been identified in any bacterial tRNA sequenced so far (for review, see Grosjean et al. 2008b)). Therefore, the presence of TrmY was not expected in bacterial genomes. In addition, the gene coding for the enzyme TrmA responsible for the formation of the canonical $\mathrm{m}^{5} \mathrm{U} 54$ in the T-loop of bacterial tRNA (Ny and Björk 1980) is found in all sequenced Vibrio genomes (VV1_1171 in Vibrio vulnificus, see COG1901 subsystem in the SEED database). The presence of COG1901 homologs in just a few bacteria could suggest that the gene family arose from a recent horizontal gene transfer event from Archaea. However, the phylogenetic analysis of the COG1901 family (Fig. 5A) shows that bacterial and archaeal COG1901 proteins form two distinct monophyletic groups, which is not easily compatible with the above hypothesis. Although the overall fold of VV2_1434 (COG1901 homolog in $V$. vulnificus) shares close structural similarity to that of Mj1640 (Z-score 26.0, RMS $1.6 \AA$, $181 \mathrm{C} \alpha$ ), significant differences for local conserved motifs and overall charge distributions are observed between these two structures (Fig. 5B). In general, VV2_1434 has a more compact structure

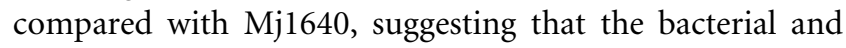
archaeal homologs may fulfill different functions. For example, Mj1640 displays short $\beta$-strands with flexible loops at the middle part of the $\beta$-sheet compared with those of VV2_1434, whereas VV2_1434 displays an extra $\alpha$-helix at its "head" of the overall "butterfly" shape (Fig. 5B). Further experimental work is required to establish the function of the bacterial COG1901 members.

This work generally reinforces the difficulty of transferring functional annotations of RNA methylases. TrmY are homologs of Nep1 but carry the same reaction (methylation of a $\Psi$ residue) in different substrates, one tRNA the other rRNA. Also, even if we have functionally characterized the function of COG1901 as TrmY in a few Archaea, some of the COG1901 homologs (for example, in Thermococcales or Bacteria) might have another function. Experimental validation of judiciously chosen members is the only solution to correctly annotating RNA methylase superfamilies.

\section{MATERIALS AND METHODS}

\section{Bioinformatics}

Sequences and distribution of all genes/proteins analyzed in this work are available through the "COG1901 sub-system" on the public SEED server (http://pubseed.theseed.org/SubsysEditor.cgi? page $=$ SubsystemOverview) (Overbeek et al. 2005). We also used 


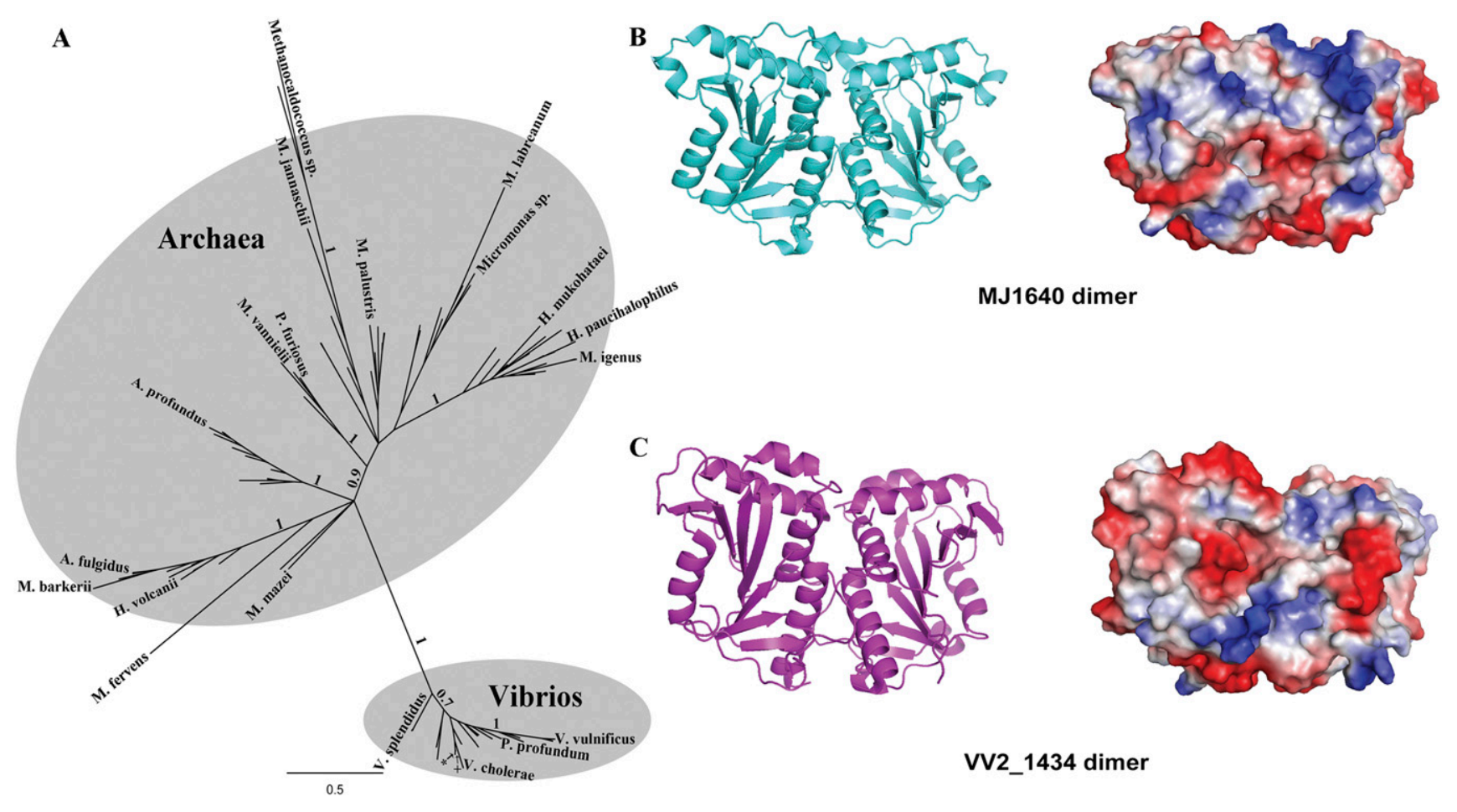

FIGURE 5. Phylogeny of the COG1901 family and structural comparison of Mj1640 dimer with VV2_1434 dimer. (A) Unrooted Bayesian tree of 42 bacterial and 72 archaeal proteins identified as COG1901 in GenBank and are listed in Supplemental file 1. For clarity, only taxa from major clades are labeled. The scale bar indicates the average number of substitutions per site. Numbers at branches represent posterior probabilities as inferred by Mr. Bayes; for clarity, only major branches are labeled. The division between Bacteria and Archaea is well supported. $\left({ }^{*}\right)$ A. borkumensis SK2; (+) S. baltica OS155, OS183, and OS185. (B) Ribbon representation of Mj1640 dimer (left); Electrostatic surface potential presentation of Mj1640 dimer (right), with blue and red colors corresponding to positively and negatively charged patches, respectively. $(C)$ Ribbon (left) and electrostatic surface potential representation (right) of VV2_1434 dimer.

the BLAST tools and resources at NCBI (Altschul et al. 1997). Multiple protein alignments were performed with the ClustalW tool (Chenna et al. 2003) in the SEED database or the MultiAlign software (http://omics.pnl.gov/). H. volcanii genome sequences were obtained from the UCSC browser (http://archaea.ucsc.edu/ cgi-bin/hgGateway? db=haloVolc1). For the phylogenetic analysis, candidate protein sequences were identified using the BLAST tool at NCBI (Altschul et al. 1997), all were COG1901 members (see Supplemental File 1 for the list of sequences used). Sequences were aligned using MUSCLE (Edgar 2004) through the EMBL-EBI website. Phylogenetic analysis was performed using MrBayes 3.1 (Ronquist and Huelsenbeck 2003) from the command line using the Dayhoff- 6 amino acid categories and inferred a tree with the $\mathrm{CAT}+\Gamma$ model to account for evolutionary rate site variations. MrBayes was run for 1,100,000 MCMC iterations with a burnin of 100,000. Trees were sampled every 1000 iterations. A consensus tree was generated and visualized using FigTree 1.3.1 (http://tree. bio.ed.ac.uk/software/figtree/).

\section{Strains, media, and transformation}

All strains used in this study are detailed in Supplemental Table S1. H. volcanii $\mathrm{H} 26$ was used as the wild-type (WT) strain. E. coli was routinely grown in LB-Lennox (LB) (Fisher) or LB agar (Fisher) at $37^{\circ} \mathrm{C}$, supplemented when required with ampicillin (Amp; $100 \mu \mathrm{g} / \mathrm{mL}$ ), isopropyl $\beta$-D-1-thiogalactopyranoside (IPTG; $0.2 \mathrm{mM}$ ), and bromo-chloro-indolyl-galactopyranoside
(X-gal; $40 \mu \mathrm{g} / \mathrm{mL}$ ). When required, novobiocin was added to a final concentration of $0.3 \mu \mathrm{g} / \mathrm{mL}$. $H$. volcanii cells were routinely grown at $44^{\circ} \mathrm{C}$ (unless specified) in rich medium (Hv-YPC) or minimal medium (Hv-min). H. volcanii media were made according to the recipes provided in the HaloHandbook (http://www.haloarchaea. com/resources/halohandbook/). Transformations of chemically competent E. coli were performed as described by the manufacturer's directions (Invitrogen). Transformation of $H$. volcanii was performed as described in the HaloHandbook using the "standard PEG-mediated transformation of Haloarchaea" protocol.

\section{Plasmid and deletion strain construction}

All plasmids and oligonucleotides used in this study are listed in Supplemental Tables S2 and S3, respectively. pIKB227, a pTA131 derivative used to disrupt trmY (HVO_1989) was produced as described previously (Blaby et al. 2010) using oligonucleotide pairs HVO1989_N_IfKO_Fwd, HVO1989_N_IfKO_Rev, HVO1989_C_ IfKO_Fwd, and HVO1989_C_IfKO_Rev to amplify the regions upstream of and downstream from the target gene. Demethylated pIKB227 was prepared by passaging the plasmid through E. coli (INV110, Invitrogen) and was subsequently used in the pop-in/ pop-out procedure (Allers et al. 2004) to delete trmY on the H. volcanii $\mathrm{H} 26$ chromosome. trm $Y$ of Halobacterium sp. NRC1 (VNG_1980C) was amplified by PCR from purified genomic DNA using Phusion Hot Start polymerase (Finnzymes, Espoo, Finland) and Hsal_cog1901_Fwd and Hsal_cog1901_Rev as prim- 
ers. The amplicon was inserted, after digestion with the compatible enzymes, between the NdeI and BlpI sites of pJAM202 to generate pIKB421 ( $\mathrm{pHTrmY}$ ). This plasmid was verified by PCR, restriction digestion, and sequencing, and then passed through E. coli (INV110, Invitrogen) before transformation into the $H$. volcanii strain VDC2376 ( $\Delta$ trmY), creating complemented strain VDC2604. Transformants were selected for by plating onto HvYPC containing novobiocin $(0.3 \mu \mathrm{g} / \mathrm{mL})$.

\section{Detection of $m^{1} \Psi$ residues in tRNAs}

For analysis by liquid chromatography-tandem mass spectrometry (LC-MS/MS), H. volcanii bulk tRNA was prepared, hydrolyzed, and analyzed as described previously (de Crécy-Lagard et al. 2010). tRNA purifications and analyses were performed at least twice independently. For analysis by $2 \mathrm{D}-\mathrm{TLC}$, uniformly ${ }^{32} \mathrm{P}$ labeled total tRNA was prepared as described before (Gupta 1984; Joardar et al. 2008). Labeled tRNAs were digested with nuclease P1 and digests were resolved on cellulose plates (EM Science) using isobutyric acid/0.5 N NH${ }_{4} \mathrm{OH}(5: 3, \mathrm{v} / \mathrm{v})$ in the first dimension and isopropanol $/ \mathrm{HCl} / \mathrm{H}_{2} \mathrm{O}(70: 15: 15, \mathrm{v} / \mathrm{v} / \mathrm{v})$ in the second dimension (Gupta 1984). Radioactivity in the plates was revealed by phosphorimaging. Presence of $\Psi$ at a specific position in tRNA was analyzed by the 1-cyclohexyl-3-(2-morpholinoethyl) carbodiimide metho$p$-toluenesulfonate (CMCT) modification technique (Ofengand et al. 2001; Motorin et al. 2007) using total small RNA. For this, initially total RNA was prepared from the cells using TRI reagent (Molecular Research Center, Inc). Small RNA fraction from the total RNA was extracted by suspending total RNA in $1 \mathrm{M} \mathrm{NaCl}$ by vigorous vortexing. The high-salt soluble fraction was separated from insoluble material by centrifugation. RNA was precipitated from the supernatant by ethanol. A total of $5 \mu \mathrm{g}$ of this RNA was treated with CMCT for 2, 10, and $20 \mathrm{~min}$ each at $37^{\circ} \mathrm{C}$, while an untreated sample was simply incubated at $37^{\circ} \mathrm{C}$ for $20 \mathrm{~min}$ as control. After precipitation of the RNA, alkali treatment was done for $3 \mathrm{~h}$ at $37^{\circ} \mathrm{C}$ for all samples except the ones treated with CMCT for $2 \mathrm{~min}$. Again, after precipitation the RNA was used for primer extension with $\left[5^{\prime}-^{32} \mathrm{P}\right]$-labeled primers that hybridized close to and on the $3^{\prime}$ side of the position to be mapped for $\Psi$. AMV reverse transcriptase (Promega) was used for primer extension according to the manufacturer's protocol, except that the reversetranscription reaction was done at $50^{\circ} \mathrm{C}$ for $1 \mathrm{~h}$ with $0.75 \mathrm{mM}$ $\mathrm{dNTP}$ each. The extension stops at one residue before the CMCT modified $\Psi$. A dark band in CMCT, followed by alkali treatment lanes, with an increased intensity in the 20-min treatment lane indicates the presence of $\Psi$ at that position. The position of the band in the gel that corresponds to $\Psi$ is determined by its distance from the end of the primer and sometimes the presence of darker bands for $\mathrm{U}$ and $\mathrm{G}$ in the 2-min CMCT, but no alkali treatment lane, and correlation with the known sequence of the RNA.

\section{Expression and purification of TrmY of $M$. jannaschii}

Recombinant TrmY protein of M. jannaschii (MJ1640) was purified as described before (Chen and Yuan 2010). These procedures are considered native conditions in this work. The protein was also prepared under renaturing conditions. For this, harvested cells were resuspended in a buffer $\left(10 \mathrm{mM} \mathrm{Na}_{2} \mathrm{HPO}_{4}, 2 \mathrm{mM} \mathrm{KH_{2 }} \mathrm{PO}_{4}, 2.7 \mathrm{mM}\right.$ $\mathrm{KCl}, 500 \mathrm{mM} \mathrm{NaCl}$ ) containing $8 \mathrm{M}$ urea, and lysed by sonication. The supernatant from a $25-\mathrm{min}$ spin at $13,000 \mathrm{rpm}$ at $4^{\circ} \mathrm{C}$ was loaded onto a $\mathrm{Ni}^{2+}$ column at room temperature equilibrated with the same buffer. The protein was renatured on the column in a gradient of $8 \mathrm{M}$ urea to no urea in the same buffer containing 2.5 $\mathrm{mM}$ imidazole. After a brief wash with $25 \mathrm{mM}$ imidazole containing buffer, the protein was eluted using $250 \mathrm{mM}$ imidazole in the same buffer. Pooled fractions were then dialyzed using $500 \mathrm{mM} \mathrm{NaCl}, 10$ mM DTT, 50 mM Tris-Cl (pH 8.0), and 20\% Glycerol.

\section{In vitro tRNA methylation assays}

Transcripts for $H$. volcanii $\mathrm{tRNA}^{\mathrm{Trp}}$ and elongator $\mathrm{tRNA}^{\mathrm{Met}}$ (lacking their introns), T-arm-Trp, and T-arm-Met were generated as described previously (Gurha et al. 2007). Mutants of tRNA $^{\text {Trp }}$ were prepared by independently changing U55 to A, $\mathrm{C}$, and $\mathrm{G}$, and of tRNA ${ }^{\text {Met }}$ by changing U54 to A as described before (Gurha et al. 2007). Sequences of these transcripts are shown in Figure 4A. Appropriate labeled transcripts were prepared using relevant $\left[\alpha-{ }^{32} \mathrm{P}\right] \mathrm{NTP}$. Recombinant $M$. jannaschii Pus10 was used first to convert U54 and U55 equivalents of these transcripts into $\Psi$ as described previously (Gurha and Gupta 2008). M. jannaschii TrmY efficiently works under a range of salt concentrations $(100-500 \mathrm{mM} \mathrm{NaCl})$. Our standard $20-\mu \mathrm{L}$ methylation reaction contained $100-150 \mathrm{nM}$ pseudouridylated RNA and $1 \mu \mathrm{M}$ renatured $M$. jannaschii TrmY in $20 \mathrm{mM}$ Tris- $\mathrm{Cl}$ (pH 7.0), $150 \mathrm{mM} \mathrm{NaCl}, 0.75 \mathrm{mM}$ DTT, $1.5 \mathrm{mM} \mathrm{MgCl} 2,0.1 \mathrm{mM}$ EDTA, $0.1 \mathrm{mM}$ AdoMet, and 5\% Glycerol. The reaction mixtures were incubated at $68^{\circ} \mathrm{C}$ for $1 \mathrm{~h}$, RNA was purified by phenol/ chloroform extraction and ethanol precipitation, and digested with RNase T2 or nuclease P1. The digests were resolved by TLC as described before for uniformly labeled tRNA. For methylation inhibition reactions, proteins isolated under native conditions were used and $0.1 \mathrm{mM}$ of S-adenosylhomocysteine, instead of AdoMet, was used in the reactions.

\section{SUPPLEMENTAL MATERIAL}

Supplemental material is available for this article.

\section{ACKNOWLEDGMENTS}

H. volcanii $\mathrm{H} 26$ was received from Julie Maupin-Furlow (University of Florida) as well as from Thorsten Allers (University of Nottingham, UK). Halobacterium sp. NRC-1 genomic DNA was prepared by Gabriela Phillips (University of Florida). Plasmid pJAM202 was a gift from Julie Maupin-Furlow. We thank Archi Joardar for providing M. jannaschii Pus10 and Sophie Alvarez for performing the LC-MS analyses, and Elisha Fitzek for analysis of archaeal Pus10 using structural criteria for functional proteins. H.G. holds a position of Emeritus Scientist at the CNRS, Centre de Génétique Moléculaire, in Gif-sur-Yvette. This work was funded in part by NIGMS (Grant no. 1RC2GM092602-01 subcontract to V.d.C.-L.), NSF (Grant no. MCB-05169448 to V.d.C.-L.), and NIH (Grant no. GM055945 to R.G.).

Received October 10, 2011; accepted December 2, 2011.

\section{REFERENCES}

Alian A, Lee TT, Griner SL, Stroud RM, Finer-Moore J. 2008. Structure of a TrmA-RNA complex: A consensus RNA fold contributes to 
substrate selectivity and catalysis in $\mathrm{m}^{5} \mathrm{U}$ methyltransferases. Proc Natl Acad Sci 105: 6876-6881.

Allers T, Ngo H, Mevarech M, Lloyd RG. 2004. Development of additional selectable markers for the halophilic archaeon Haloferax volcanii based on the leuB and trpA genes. Appl Environ Microbiol 70: 943-953.

Altschul SF, Madden TL, Schaffer AA, Zhang J, Zhang Z, Miller W, Lipman DJ. 1997. Gapped BLAST and PSI-BLAST: a new generation of protein database search programs. Nucleic Acids Res 25: 3389-3402.

Auxilien S, Rasmussen A, Rose S, Brochier-Armanet Cl, Husson C, Fourmy D, Grosjean H, Douthwaite S. 2011. Specificity shifts in the rRNA and tRNA nucleotide targets of archaeal and bacterial $\mathrm{m}^{5} \mathrm{U}$ methyltransferases. RNA 17: 45-53.

Bakin AV, Ofengand J. 1998. Mapping of pseudouridine residues in RNA to nucleotide resolution. Methods Mol Biol 77: 297-309.

Becker HF, Motorin Y, Sissler M, Florentz C, Grosjean H. 1997. Major identity determinants for enzymatic formation of ribothymidine and pseudouridine in the T $\psi$-loop of yeast tRNAs. J Mol Biol 274: 505-518.

Best AN. 1978. Composition and characterization of tRNA from Methanococcus vannielii. J Bacteriol 133: 240-250.

Blaby IK, Phillips G, Blaby-Haas CE, Gulig KS, El Yacoubi B, de Crécy-Lagard V. 2010. Towards a systems approach in the genetic analysis of archaea: accelerating mutant construction and phenotypic analysis in Haloferax volcanii. Archaea 2010: 426239. doi: $10.1155 / 2010 / 426239$.

Brand RC, Klootwijk J, Planta RJ, Maden BE. 1978. Biosynthesis of a hypermodified nucleotide in Saccharomyces carlsbergensis $17 \mathrm{~S}$ and HeLa-cell $18 S$ ribosomal ribonucleic acid. Biochem J 169: 7177.

Buchhaupt M, Meyer B, Kötter P, Entian K-D. 2006. Genetic evidence for $18 \mathrm{~S}$ rRNA binding and an Rps19p assembly function of yeast nucleolar protein Neplp. Mol Genet Genomics 276: 273-284.

Cantara WA, Crain PF, Rozenski J, McCloskey JA, Harris KA, Zhang X, Vendeix FAP, Fabris D, Agris PF. 2011. The RNA modification database, RNAMDB: 2011 update. Nucleic Acids Res 39: D195D201.

Chen H-Y, Yuan YA. 2010. Crystal structure of Mj1640/DUF358 protein reveals a putative SPOUT-class RNA methyltransferase. J Mol Cell Biol 2: 366-374.

Chenna R, Sugawara H, Koike T, Lopez R, Gibson TJ, Higgins DG, Thompson JD. 2003. Multiple sequence alignment with the Clustal series of programs. Nucleic Acids Res 31: 3497-3500.

Constantinesco F, Motorin Y, Grosjean H. 1999. Transfer RNA modification enzymes from Pyrococcus furiosus: detection of the enzymatic activities in vitro. Nucleic Acids Res 27: 1308-1315.

Crain PF. 1990. Preparation and enzymatic hydrolysis of DNA and RNA for mass spectrometry. Methods Enzymol 193: 782-790.

Czerwoniec A, Dunin-Horkawicz S, Purta E, Kaminska KH, Kasprzak JM, Bujnicki JM, Grosjean H, Rother K. 2009. MODOMICS: a database of RNA modification pathways. 2008 update. Nucleic Acids Res 37: D118-D121.

de Crécy-Lagard V, Brochier-Armanet C, Urbonavicius J, Fernandez B, Phillips G, Lyons B, Noma A, Alvarez S, Droogmans L, Armengaud J, et al. 2010. Biosynthesis of wyosine derivatives in tRNA: an ancient and highly diverse pathway in Archaea. Mol Biol Evol 27: 2062-2077.

Edgar RC. 2004. MUSCLE: multiple sequence alignment with high accuracy and high throughput. Nucleic Acids Res 32: 17921797.

Edmonds CG, Vestal ML, McCloskey JA. 1985. Thermospray liquid chromatography-mass spectrometry of nucleosides and of enzymatic hydrolysates of nucleic acids. Nucleic Acids Res 13: 81978206.

Edmonds CG, Crain PF, Gupta R, Hashizume T, Hocart CH, Kowalak JA, Pomerantz SC, Stetter KO, McCloskey JA. 1991. Posttranscriptional modification of tRNA in thermophilic archaea (Archaebacteria). J Bacteriol 173: 3138-3148.
Grosjean H. 2009. Nucleic Acids are not boring long polymers of only four types of nucleotides. In DNA and RNA modification enzymes: Structure, mechanism, function and evolution (ed. H Grosjean), pp. 1-18. Landes Bioscience, Austin, TX.

Grosjean H, Constantinesco F, Foiret D, Benachenhou N. 1995. A novel enzymatic pathway leading to 1-methylinosine modification in Haloferax volcanii tRNA. Nucleic Acids Res 23: 4312-4319.

Grosjean H, Edqvist J, Straby KB, Giegé R. 1996. Enzymatic formation of modified nucleosides in tRNA: dependence on tRNA architecture. J Mol Biol 255: 67-85.

Grosjean H, Droogmans L, Roovers M, Keith G. 2007. Detection of enzymatic activity of transfer RNA modification enzymes using radiolabeled tRNA substrates. Methods Enzymol 425: 55-101.

Grosjean H, Gaspin C, Marck C, Decatur WA, de Crécy-Lagard V. 2008a. RNomics and Modomics in the halophilic archaea Haloferax volcanii: identification of RNA modification genes. BMC Genomics 9: 470. doi: 10.1186/1471-2164-9-470.

Grosjean H, Gupta R, Maxwell ES. 2008b. Modified nucleotides in Archaeal RNAs. In Archaea: New models for prokaryotic biology (ed. P Blum), pp. 171-196. Horizon Scientific Press, Caister Academic Press, Cambridge, UK.

Gu X-R, Nicoghosian K, Cedergren RJ, Wong JT-F. 1983. Sequences of halobacterial tRNAs and the paucity of $U$ in the first position of their anticodons. Nucleic Acids Res 11: 5433-5442.

Gu X-R, Nicoghosian K, Cedergren RJ. 1984. Glycine and asparagme tRNA sequences from the archaebacteriuin, Methanobacterium thermoautotrophicum. FEBS Lett 176: 462-466.

Gu X, Ivanetich KM, Santi DV. 1996. Recognition of the T-arm of tRNA by tRNA ( $\left.\mathrm{m}^{5} \mathrm{U} 54\right)$-methyltransferase is not sequence specific. Biochemistry 35: 11652-11659.

Gupta R. 1984. Halobacterium volcanii tRNAs: identification of 41 tRNAs covering all amino acids, and the sequences of 33 Class I tRNAs. J Biol Chem 259: 9461-9471.

Gupta R. 1986. Transfer RNAs of Halobacterium volcanii: sequences of five leucine and three serine tRNAs. Syst Appl Microbiol 7: 102105.

Gupta R, Woese C. 1980. Unusual modification patterns in the transfer ribonucleic acids of archaebacteria. Curr Microbiol 4: 245-249.

Gurha P, Gupta R. 2008. Archaeal Pus10 proteins can produce both pseudouridine 54 and 55 in tRNA. RNA 14: 2521-2527.

Gurha P, Joardar A, Chaurasia P, Gupta R. 2007. Differential roles of archaeal box H/ACA proteins in guide RNA-dependent and independent pseudouridine formation. RNA Biol 4: 101-109.

Gutgsell N, Englund N, Niu L, Kaya Y, Lane BG, Ofengand J. 2000. Deletion of the Escherichia coli pseudouridine synthase gene truB blocks formation of pseudouridine 55 in tRNA in vivo, does not affect exponential growth, but confers a strong selective disadvantage in competition with wild-type cells. RNA 6: 1870-1881.

Joardar A, Gurha P, Skariah G, Gupta R. 2008. Box C/D RNA-guided $2^{\prime}-\mathrm{O}$ methylations and the intron of tRNA ${ }^{\text {TrP }}$ are not essential for the viability of Haloferax volcanii. J Bacteriol 190: 7308-7313.

Kilpatrick MW, Walker RT. 1981. The nucleotide sequence of the tRNA $_{M}{ }^{\text {Met }}$ from the archaebacterium Thermoplasma acidophilum. Nucleic Acids Res 9: 4387-4390.

Kinghorn SM, O’Byrne CP, Booth IR, Stansfield I. 2002. Physiological analysis of the role of truB in Escherichia coli: a role for tRNA modification in extreme temperature resistance. Microbiology 148: 3511-3520.

Kotlova N, Ishii TM, Zagryadskaya EI, Steinberg SV. 2007. Active suppressor tRNAs with a double helix between the D- and T-loops. J Mol Biol 373: 462-475.

Kowalak JA, Dalluge JJ, McCloskey JA, Stetter KO. 1994. The role of posttranscriptional modification in stabilization of transfer RNA from hyperthermophiles. Biochemistry 33: 7869-7876.

Kowalak JA, Bruenger E, Crain PF, McCloskey JA. 2000. Identities and phylogenetic comparisons of posttranscriptional modifications in 16 S ribosomal RNA from Haloferax volcanii. J Biol Chem 275: 24484-24489. 
Kuchino Y, Ihara M, Yabusaki Y, Nishimura S. 1982. Initiator tRNAs from archaebacteria show common unique sequence characteristics. Nature 298: 684-685.

Lee TT, Agarwalla S, Stroud RM. 2005. A unique RNA fold in the RumA-RNA-cofactor ternary complex contributes to substrate selectivity and enzymatic function. Cell 120: 599-611.

Leulliot N, Bohnsack MT, Graille M, Tollervey D, Van Tilbeurgh H. 2008. The yeast ribosome synthesis factor Emg1 is a novel member of the superfamily of $\alpha / \beta$ knot fold methyltransferases. Nucleic Acids Res 36: 629-639.

Marck C, Grosjean H. 2002. tRNomics: analysis of tRNA genes from 50 genomes of Eukarya, Archaea, and Bacteria reveals anticodonsparing strategies and domain-specific features. RNA 8: 1189-1232.

Meyer B, Wurm JP, Kötter P, Leisegang MS, Schilling V, Buchhaupt M, Held M, Bahr U, Karas M, Heckel A, et al. 2011. The BowenConradi syndrome protein Nep1 (Emg1) has a dual role in eukaryotic ribosome biogenesis, as an essential assembly factor and in the methylation of $\Psi 1191$ in yeast $18 \mathrm{~S}$ rRNA. Nucleic Acids Res 39: 1526-1537.

Motorin Y, Helm M. 2011. RNA nucleotide methylation. Wiley Interdiscip Rev RNA 2: 611-631.

Motorin Y, Muller S, Behm-Ansmant I, Branlant C. 2007. Identification of modified residues in RNAs by reverse transcription-based methods. Methods Enzymol 425: 21-53.

Nicoghosian K, Gu X-R, Cedergren R. 1985. Halobacterium cutirubrum tRNA sequences. FEBS Lett 193: 255-260.

Nishikura K, De Robertis EM. 1981. RNA processing in microinjected Xenopus oocytes. Sequential addition of base modifications in the spliced transfer RNA. J Mol Biol 145: 405-420.

Noon KR, Guymon R, Crain PF, McCloskey JA, Thomm M, Lim J, Cavicchioli R. 2003. Influence of temperature on tRNA modification in Archaea: Methanococcoides burtonii (Optimum Growth Temperature $\left.\left[T_{\mathrm{opt}}\right], 23^{\circ} \mathrm{C}\right)$ and Stetteria hydrogenophila $\left(T_{\mathrm{opt}}\right.$, 95 $\left.{ }^{\circ} \mathrm{C}\right) . J$ Bacteriol 185: 5483-5490.

Ny T, Björk GR. 1980. Cloning and restriction mapping of the trmA gene coding for transfer ribonucleic acid (5-methyluridine)methyltransferase in Escherichia coli K-12. J Bacteriol 142: 371-379.

Ofengand J, Del Campo M, Kaya Y. 2001. Mapping pseudouridines in RNA molecules. Methods 25: 365-373.

Overbeek R, Begley T, Butler RM, Choudhuri JV, Chuang HY, Cohoon M, de Crécy-Lagard V, Diaz N, Disz T, Edwards R, et al. 2005. The subsystems approach to genome annotation and its use in the project to annotate 1000 genomes. Nucleic Acids Res Symp Series 33: 5691-5702.
Pang H, Ihara M, Kuchino Y, Nishimura S, Gupta R, Woese CR, McCloskey JA. 1982. Structure of a modified nucleoside in archaebacterial tRNA which replaces ribosylthymine. 1-Methylpseudouridine. J Biol Chem 257: 3589-3592.

Romby P, Carbon P, Westhof E, Ehresmann C, Ebel JP, Ehresmann B, Giegé R. 1987. Importance of conserved residues for the conformation of the T-loop in tRNAs. J Biomol Struct Dyn 5: 669-687.

Ronquist F, Huelsenbeck JP. 2003. MrBayes 3: Bayesian phylogenetic inference under mixed models. Bioinformatics 19: 15721574.

Tatusov R, Fedorova N, Jackson J, Jacobs A, Kiryutin B, Koonin E, Krylov D, Mazumder R, Mekhedov S, Nikolskaya A, et al. 2003. The COG database: an updated version includes eukaryotes. $B M C$ Bioinformatics 4: 41. doi: 10.1186/1471-2105-4-41.

Taylor AB, Meyer B, Leal BZ, Kötter P, Schirf V, Demeler B, Hart PJ, Entian K-D, Wöhnert J. 2008. The crystal structure of Nep1 reveals an extended SPOUT-class methyltransferase fold and a pre-organized SAM-binding site. Nucleic Acids Res 36: 1542-1554.

Thomas SR, Keller CA, Szyk A, Cannon JR, LaRonde-LeBlanc NA. 2011. Structural insight into the functional mechanism of Nep1/ Emg1 N1-specific pseudouridine methyltransferase in ribosome biogenesis. Nucleic Acids Res 39: 2445-2457.

Tkaczuk K, Dunin-Horkawicz S, Purta E, Bujnicki J. 2007. Structural and evolutionary bioinformatics of the SPOUT superfamily of methyltransferases. BMC Bioinformatics 8: 73. doi: 10.1186/14712105-8-73.

Urbonavicius J, Auxilien S, Walbott H, Trachana K, GolinelliPimpaneau B, Brochier-Armanet C, Grosjean H. 2008. Acquisition of a bacterial RumA-type tRNA(uracil-54, C5)-methyltransferase by Archaea through an ancient horizontal gene transfer. Mol Microbiol 67: 323-335.

Walbott H, Leulliot N, Grosjean H, Golinelli-Pimpaneau B. 2008. The crystal structure of Pyrococcus abyssi tRNA (uracil-54, C5)-methyltransferase provides insights into its tRNA specificity. Nucleic Acids Res 36: 4929-4940.

Wurm JP, Meyer B, Bahr U, Held M, Frolow O, Kotter P, Engels JW, Heckel A, Karas M, Entian KD, et al. 2010. The ribosome assembly factor Nep1 responsible for Bowen-Conradi syndrome is a pseudouridine-N1-specific methyltransferase. Nucleic Acids Res 38: 2387-2398.

Youvan DC, Hearst JE. 1981. A sequence from Drosophila melanogaster 18S rRNA bearing the conserved hypermodified nucleoside am $\psi$ : analysis by reverse transcription and high-performance liquid chromatography. Nucleic Acids Res 9: 1723-1742. 

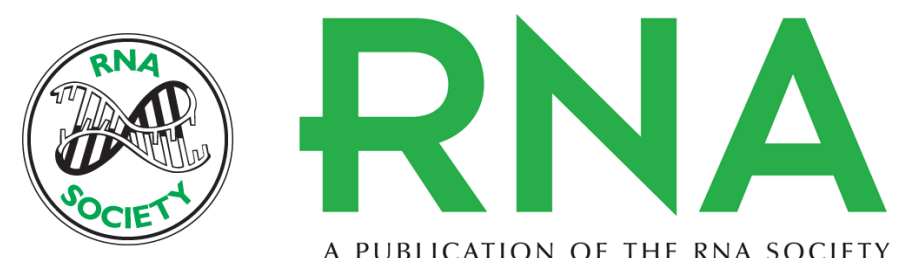

A PUBLICATION OF THE RNA SOCIETY

\section{The archaeal COG1901/DUF358 SPOUT-methyltransferase members, together with pseudouridine synthase Pus10, catalyze the formation of 1-methylpseudouridine at position 54 of tRNA}

Kunal Chatterjee, Ian K. Blaby, Patrick C. Thiaville, et al.

RNA 2012 18: 421-433 originally published online January 24, 2012

Access the most recent version at doi:10.1261/rna.030841.111

Supplemental Material

Related Content

References

License

Email Alerting

Service
http://rnajournal.cshlp.org/content/suppl/2012/01/05/rna.030841.111.DC1

Identification of the enzyme responsible for N1-methylation of pseudouridine 54 in archaeal tRNAs

Jan Philip Wurm, Marco Griese, Ute Bahr, et al.

RNA March , 2012 18: 412-420

This article cites 63 articles, 15 of which can be accessed free at:

http://rnajournal.cshlp.org/content/18/3/421.full.html\#ref-list-1

Articles cited in:

http://rnajournal.cshlp.org/content/18/3/421.full.html\#related-urls

Receive free email alerts when new articles cite this article - sign up in the box at the top right corner of the article or click here.

To subscribe to RNA go to:

http://rnajournal.cshlp.org/subscriptions 